Article

\title{
Investigations on Melt Flow Rate and Tensile Behaviour of Single, Double and Triple-Sized Copper Reinforced Thermoplastic Composites
}

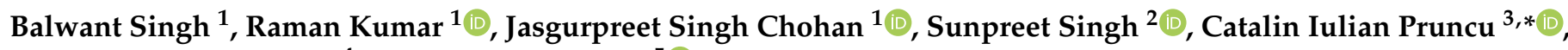 \\ Maria Luminita Scutaru ${ }^{4, *}$ and Radu Muntean ${ }^{5}$ (D) \\ 1 Department of Mechanical Engineering, Chandigarh University, Mohali 140413, India; \\ balwant.e1941@cumail.in (B.S.); raman.me@cumail.in (R.K.); jasgurpreet.me@cumail.in (J.S.C.) \\ 2 Department of Mechanical Engineering, National University of Singapore, Singapore 117575, Singapore; \\ snprt.singh@gmail.com \\ 3 Design, Manufacturing and Engineering Management, University of Strathclyde, Glasgow G4 0LN, UK \\ 4 Department of Mechanical Engineering, Transilvania University of Brasov, 500036 Brasov, Romania \\ 5 Department of Civil Engineering, Transilvania University of Brasov, 500036 Brasov, Romania; \\ radu.m@unitbv.ro \\ * Correspondence: Catalin.pruncu@strath.ac.uk (C.I.P.); lscutaru@unitbv.ro (M.L.S.)
}

Citation: Singh, B.; Kumar, R.; Chohan, J.S.; Singh, S.; Pruncu, C.I.; Scutaru, M.L.; Muntean, R.

Investigations on Melt Flow Rate and Tensile Behaviour of Single, Double and Triple-Sized Copper Reinforced Thermoplastic Composites. Materials 2021, 14, 3504. https://doi.org/ $10.3390 /$ ma14133504

Academic Editor: Naozumi Teramoto

Received: 28 April 2021

Accepted: 16 June 2021

Published: 23 June 2021

Publisher's Note: MDPI stays neutral with regard to jurisdictional claims in published maps and institutional affiliations.

Copyright: (c) 2021 by the authors. Licensee MDPI, Basel, Switzerland. This article is an open access article distributed under the terms and conditions of the Creative Commons Attribution (CC BY) license (https:// creativecommons.org/licenses/by/ $4.0 /)$

\begin{abstract}
Thermoplastic composite materials are emerging rapidly due to the flexibility of attaining customized mechanical and melt flow properties. Due to high ductility, toughness, recyclability, and thermal and electrical conductivity, there is ample scope of using copper particles in thermoplastics for $3 \mathrm{~d}$ printing applications. In the present study, an attempt was made to investigate the Melt Flow Index (MFI), tensile strength, and electrical and thermal conductivity of nylon 6 and ABS (acrylonitrile butadiene styrene) thermoplastics reinforced with copper particles. Thus, the experiments were conducted by adding different-sized copper particles (100 mesh, 200 mesh, and 400 mesh) in variable compositions ( $0 \%$ to $10 \%$ ) to ABS and nylon 6 matrix. The impact of single, double, and triple particle-sized copper particles on MFI was experimentally investigated followed by FTIR and SEM analysis. Also, the tensile, electrical, and thermal conductivity testing were done on filament made by different compositions. In general, higher fluidity and mechanical strength were obtained while using smaller particles even with higher concentrations (up to $8 \%$ ) due to improved bonding strength and adhesion between the molecular chains. Moreover, thermal and electrical conductivity was improved with an increase in concentration of copper particles.
\end{abstract}

Keywords: polymer matrix composites; Melt Flow Index; Nylon 6; ABS; copper particles

\section{Introduction}

The use of polymer matrix composites has been increasing day-by-day due to vast engineering applications of these materials [1,2]. Polymers are preferred for fabrication of light-weight components involving lower manufacturing cost and lead time. Due to unique characteristics of polymers such as higher toughness, resilience, corrosion resistance, flexibility, and strength to weight ratio, they have completely replaced metals for certain application areas [3,4]. Polymer matrix composites have been developed to induce customized characteristics and further enhance the scope of applications. Metal particles are added to polymer matrices to improve stiffness, fatigue resistance, wear resistance, specific strength, and conductivity of products. Metal-based polymer matrix composites are in high demand in a variety of fields, including automotive, aerospace, civil, electronics, communications, sports, marine, military, building, and various household items [5,6]. Recent investigations have demonstrated that, in general, the physical, mechanical, electrical, and thermal properties of polymers are improved with the addition of reinforcements [7]. Tekce et al. [8] reported an increase in thermal conductivity of polymers with the addition of 
copper particles and found a higher role of particle size, shape, and concentration. Copperbased polymer composites are essentially used by electronic industries as higher electrical and thermal conductivity is achieved [9]. Although numerous technologies are available for production of polymer composites, Fused Deposition Modeling (FDM) has evolved as a promising technique, as products with customized designs can be prepared. Furthermore, desired properties can be induced through FDM by varying the manufacturing conditions and concentration of reinforcements while maintaining minimum production cost and time [10].

The raw material for FDM is a thermoplastic filament that can be prepared through extrusion process. Boparai et al. [11] explored the possibilities of using polymer composite filament through extrusion for rapid prototyping and tooling. It was emphasized that the melt flow rate of composite filament must match with virgin material to ensure uniform extrusion during the FDM process. The significant variation in melt flow rate results in practical problems such as nozzle clogging, filament breakage, porous structure, nonuniform heating etc. Thus, the study of melt flow rate and thermal and mechanical strength of filaments is desirable during the development of polymer composites using FDM [12].

Numerous studies on strength and fluidity of composites prepared through screw extrusion and FDM process have been reported by researchers. Hamzah et al. [13] investigated the mechanical, electrical, and thermal characteristics of Acrylonitrile Butadiene Styrene (ABS) reinforced with Copper Ferrite $\left(\mathrm{CuFe}_{2} \mathrm{O}_{4}\right)$ with three different weight proportions $(8 \%, 11 \%$ and $14 \%)$. So, it was concluded that the specimens that were reinforced with $14 \% \mathrm{CuFe}_{2} \mathrm{O}_{4}$ particles exhibited $135 \%$ improvement in tensile strength. The study suggests considerable interlocking of $\mathrm{CuFe}_{2} \mathrm{O}_{4}$ filler with $\mathrm{ABS}$ matrix, which enhanced its bonding strength and hence provided resistance to tensile loading. Due to greater resistance to plastic deformation, a $14 \%$ rise in ABS hardness was measureded with the addition of $14 \%$ $\mathrm{CuFe}_{2} \mathrm{O}_{4}$. The thermal conductivity was improved by $93 \%$ and also electrical conductivity was significantly improved by adding $\mathrm{CuFe}_{2} \mathrm{O}_{4}$ in ABS. Shahmirzadi et al. [14] studied the rheological and morphological properties of composites prepared by addding copper particles to Polypropylene matrix. It was reported that the melt flow rate of feedstock filament decreased to one third as the concentration of copper particles increased from $50 \%$ to $60 \%$. In the case of feedstock, this fluidity reduction occurred due to improper mixing of copper powder and binder. It was concluded that for better mixing of powder and binder, time and temperature of mixing are two critical parameters. Moreover, the particle size of the copper powder played an important role during rheological testing. Better electrical and thermal conductivity was achieved with lower particle size due to uniform distribution of copper even at higher concentrations. Isa et al. [15] reported an increase in melt flow rate of ABS composites with the addition of $50 \mu \mathrm{m}$ copper reinforcements. It was found that melting temperature and mixing conditions significantly affect the fluidity of composites. Nikzad et al. [16] studied the mechanical and thermal properties of specimens manufactured by $40 \%$ addition of iron particles in ABS matrix. The thermal and mechanical properties of composites were enhanced as compared to virgin materials, which highlighted the importance of metallic fillers. Singh et al. [17] investigated the torsion and tensile behavior of ABS-clay nanocomposites with morphological and rheological characterizations. ABS nano-composites were manufactured in a twin-screw extruder machine by mixing them with the various levels of nanoclay (Cloisite 30B) followed by characterization. It was concluded that the addition of nanoclay to ABS improved the modulus of elasticity and modulus of rigidity under torsional load.

Despite extensive literature being available on composites prepared through extrusion, there is a need to investigate the impact of different copper particle sizes and concentrations on melt flow rate, and tensile, thermal, and electrical properties of composite filament. The present study was conducted to explore the possibility of using copper-reinforced 3d-printed thermoplastic polymer for electronic components. Recent studies have reported an increase in electrical and thermal conductivity of polymers with the addition of copper particles $[18,19]$. Hence, the customized electronic components can be prepared from 
copper-based polymer composites using FDM process. Also, the impact of combinations of different particles sizes on melt flow, mechanical, and morphological properties of composite filament have not yet been explored. ABS and nylon 6 are selected as matrix material, as these are extensively used by electronics industry for making casings, enclosures, cooling fan blades, wearable devices, and cabinets. Higher thermal conductivity of composite material ensures faster dissipation, which further prevents overheating of electronic parts. Moreover, the electrical conductivity induced by copper doping finds vast applications in sensors and metamaterials. The findings of this study would help to select suitable composition and combination of copper particles for preparing composite filament with desired mechanical, thermal, and electrical properties, and flow rate. The composite filament can be further used for fabrication of customized electronic products.

\section{Materials and Methods}

Nylon 6 and ABS are used as base materials to prepare composite filaments during present experimentation. Nylon 6 is a thermoplastic material that is chemically resistive and abrasion resistive. Its glass transition temperature is $47^{\circ} \mathrm{C}$, melting temperature is $220^{\circ} \mathrm{C}$, and density is $1.31 \mathrm{~g} / \mathrm{cm}^{3}$. Because of these properties, the nylon 6 is generally used in the production of gears and bearings used in the automotive industry. ABS is a low-cost engineering thermoplastic material that has properties such as impact resistance and rigidity, but it can be easily machined, processed, and thermoformed. ABS provides a good balance of resistance to heat, dimensional stability, high tensile strength, high stiffness, and insulating properties [20]. The majority of natural ABS resins are translucent to opaque, but they can be manufactured in transparent grades and almost any color can be pigmented [21]. For certain outdoor applications, general-purpose grades can work, but constant sun exposure causes the color change. The constant exposure also decreases material gloss, toughness, fracture toughness, and modulus of elasticity. The ABS melting temperature ranges from $221-240{ }^{\circ} \mathrm{C}$, and the density is $1.07 \mathrm{~g} / \mathrm{cm}^{3}$ [22]. Copper, having a melting point of $1083^{\circ} \mathrm{C}$, has many advantageous properties such as corrosion resistivity and strong electrical and thermal properties [23]. For the present research, the nylon 6 and ABS material was supplied by Batra Polymers Pvt. Ltd., Ludhiana, India. On the other hand, copper particles of different sizes were purchased from Shri Manak Copper Pvt. Ltd., Jaipur, India.

Nylon 6 and ABS (acrylonitrile butadiene styrene) were used as a matrix material while copper particles of three different sizes (100 mesh, 200 mesh, 400 mesh) were used as a reinforcement material (see Figure 1). Some of the properties of copper particles have been displayed in Table 1.

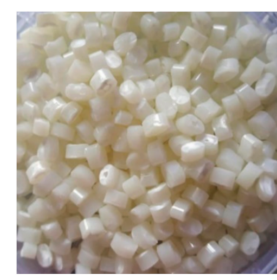

(a)

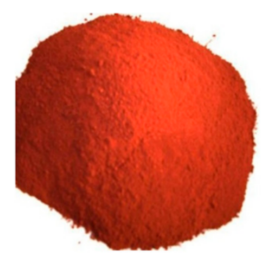

(c)

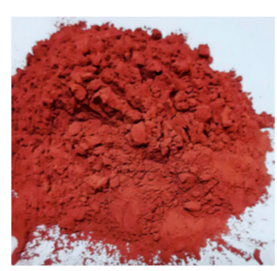

(d)

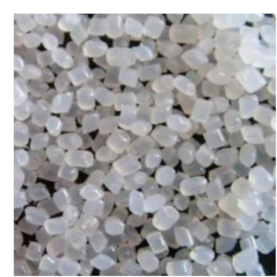

(b)

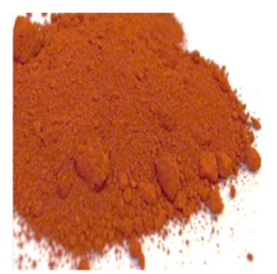

(e)

Figure 1. Images of: (a) ABS, (b) nylon 6, (c) 100 mesh copper powder, (d) 200 mesh copper powder, and (e) 400 mesh copper powder. 
The density of 100 mesh, 200 mesh, and 400 mesh copper particles is $1.32 \mathrm{~g} / \mathrm{cc}$, $1.22 \mathrm{~g} / \mathrm{cc}$, and $1.29 \mathrm{~g} / \mathrm{cc}$ respectively. The selection of different particle sizes was done based on previous literature as particle shape and size have a significant effect on product characteristics $[8,24]$. Using different combinations, the composite material with customized strength and flow rate can be prepared as per requirement. This finds practical applications where weight and cost must be optimized as per strength requirement to save product cost. Since copper is costly as compared to polymers, the product cost can be reduced by controlling particle size and combination.

Table 1. Properties of copper particles.

\begin{tabular}{cccc}
\hline Characteristics & Test Method & Specification & Test Results \\
\hline Apparent Density (g/cc) & IS4848 [25] & $1.0-1.4$ & 1.32 \\
Sieve Analysis (\%) & IS460 [26] & $100 \%$ & $100 \%$ \\
Particle Shape & Light Optical & Dendritic & Dendritic \\
Color & Microscopy & Reddish Brown & Reddish Brown \\
Flow Rate (Sec/50 g) & IS 4840 [27] & $50-60$ & 60 \\
Chemical Analysis (\%) & IS 440 [28] & 99.8 Min & 99.9 \\
\hline
\end{tabular}

Figure 2 describes the detailed methodology adopted to complete the present experimental work. Initially, the nylon 6 material and ABS (acrylonitrile butadiene styrene) thermoplastics were selected for the research work with the different compositions of copper particles of variable (100 mesh, 200 mesh, and 400 mesh) sizes. After the selection of materials, composite mixtures were prepared using different sizes and different proportions. In the present work, first of all, single-particle size compositions were prepared using the weighing machine in which three composite materials were prepared each with ABS and nylon 6 as the matrix. Secondly, double particle size compositions were prepared by mixing each thermoplastic with two different sizes of copper particles. Thirdly, triple particle size compositions were prepared by mixing equal proportions of three sizes of copper particles. In this research work, the notations are given to each type of composition as shown in Table 2. After the preparation of all compositions, the Melt Flow Rate was measured with the help of Melt Flow Indexer through which the fluidity of the material could be ascertained. The tensile testing of different compositions was performed with the help of the Universal Testing Machine. At last, the characterization was done with the help of the Scanning Electron Microscope (SEM) and Fourier Transform Infrared Spectroscopy (FTIR).

Table 2. Nomenclature of different compositions.

\begin{tabular}{ccc}
\hline Serial Number & Particle Size and Compositions & Notation \\
\hline 1. & 100 mesh Copper Particles & $A$ \\
2. & 200 mesh Copper Particles & $C$ \\
3. & 400 mesh Copper Particles & 1 \\
4. & $1 \%$ Copper and $99 \%$ Nylon 6 & 2 \\
5. & $2.5 \%$ Copper and $97.5 \%$ Nylon 6 & 3 \\
6. & $5 \%$ Copper and $95 \%$ Nylon 6 & 4 \\
7. & $1 \%$ Copper and $99 \%$ ABS & 5 \\
8. & $2.5 \%$ Copper and $97.5 \%$ ABS & 6 \\
9. & $5 \%$ Copper and $95 \%$ ABS & 7 \\
10. & $8 \%$ Copper and $92 \%$ ABS & 8 \\
11. & $10 \%$ Copper and $90 \%$ ABS & 9 \\
12. & $3 \%$ Copper and $97 \%$ ABS & 10 \\
13. & $6 \%$ Copper and $94 \%$ ABS & 11 \\
14. & $3 \%$ Copper and $97 \%$ Nylon 6 & 12 \\
15. & $6 \%$ Copper and $94 \%$ Nylon 6 & 13 \\
16. & $8 \%$ Copper and $92 \%$ Nylon 6 & 14 \\
17. & $8 \%$ Copper and $92 \%$ ABS & \\
\hline
\end{tabular}




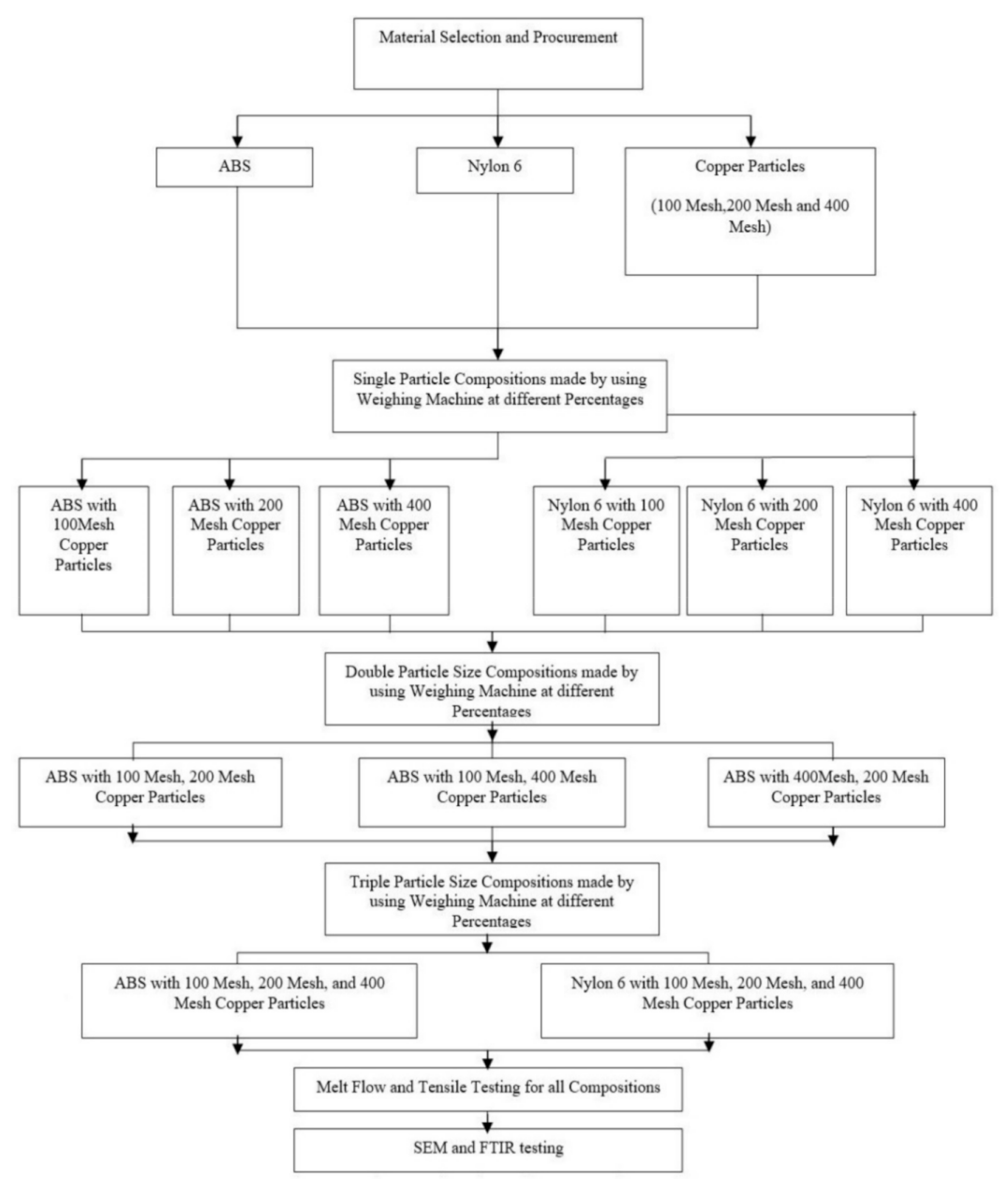

Figure 2. Flow chart of present study.

\subsection{Melt Flow Index Testing}

Melt Flow Index (MFI) of polymer composites was measured to ascertain their flow rate, which is necessary for its usability in FDM. This test simply measures the weight ratio of the flow rate of polymers or polymer composites over a given time and temperature range. ASTM D1238 is just one particular standard that has been used for Melt Flow Index (MFI) testing [29]. This method is one of the most common methods used by different industries when describing the exact fluidity of the material. The experiments were performed in this study using the melt indexer machine (MIM) [30]. Initially, the MIM was preheated at $220^{\circ} \mathrm{C}$ for around $30 \mathrm{~min}$ and afterward, $5-8 \mathrm{~g}$ of the mixture was loaded in the MIM. A piston load of $2.180 \mathrm{~kg}$ was mounted on the piston rod, and a stopwatch was used to read $25.4 \mathrm{~mm}$ in length. A filament was extruded in the vertical direction according to gravity flow. During the present experimentation work, the MIM (see Figure 3) used to test the melt flow rate of polymer composite was Model: TC-SW-20-E supplied by Shanta Engineering Pvt. Ltd., Pune, India. With a temperature range of ambient to $400{ }^{\circ} \mathrm{C}$, the MIM was equipped with a Microprocessor-based PID Temperature Controller having $0.1^{\circ} \mathrm{C}$ resolution. 


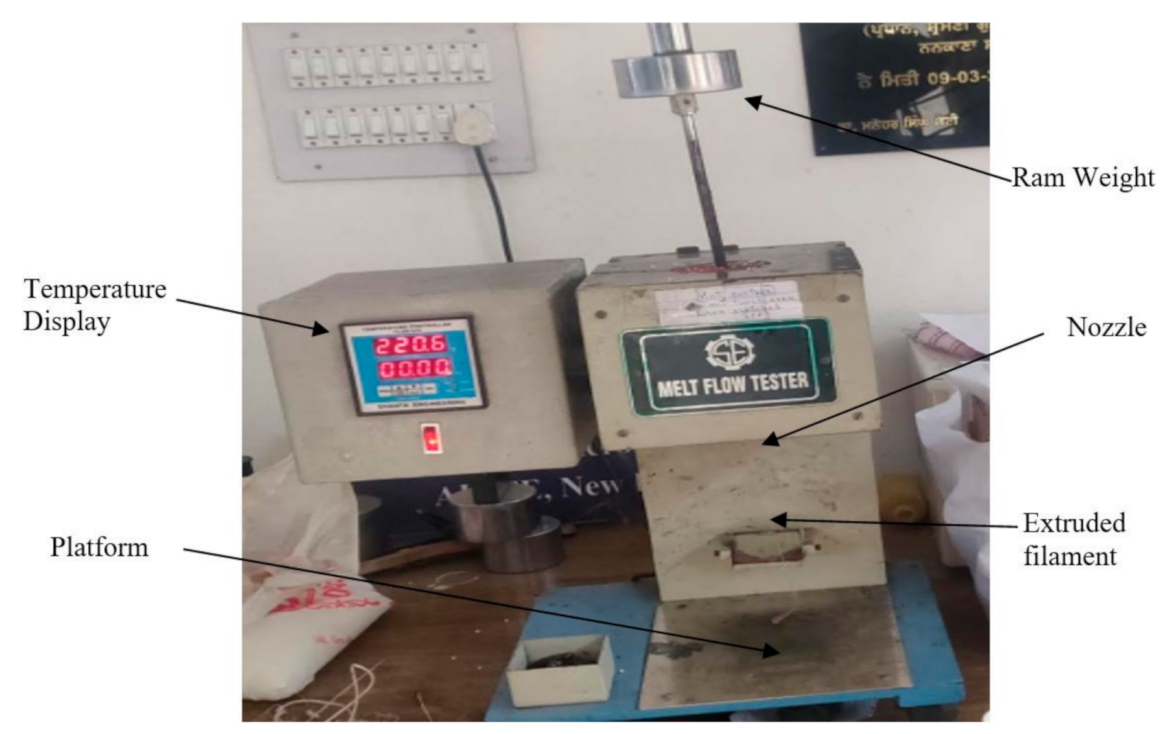

Figure 3. Melt indexer machine.

\subsection{Universal Testing Machine}

To acquire the tensile properties of polymer composites such as peak load, break load, peak elongation, and breaking elongation, the universal testing machine was used [31]. In the present experiment, we used universal testing machine manufactured by Shanta Engineering Pvt. Ltd., Pune, India (Model: Standard Twin Column) as shown in Figure 4. This machine has a pulley belt system that allows for the selection of different speeds. It also has the ability to mount numerous load cells as well as grips and fixtures for various tests and materials such as rubber, plastics, cables, leather, paper, plywood, and polymer composites. A motorized test frame is driven by twin ball screws featuring dual columns and designed to apply tension ranging from $2 \mathrm{~N}$ to $50 \mathrm{kN}$. The tensile testing was performed following ASTM D4018-17 standards using composite filament of diameter $1.75 \mathrm{~mm}$ and length $90 \mathrm{~mm}$.

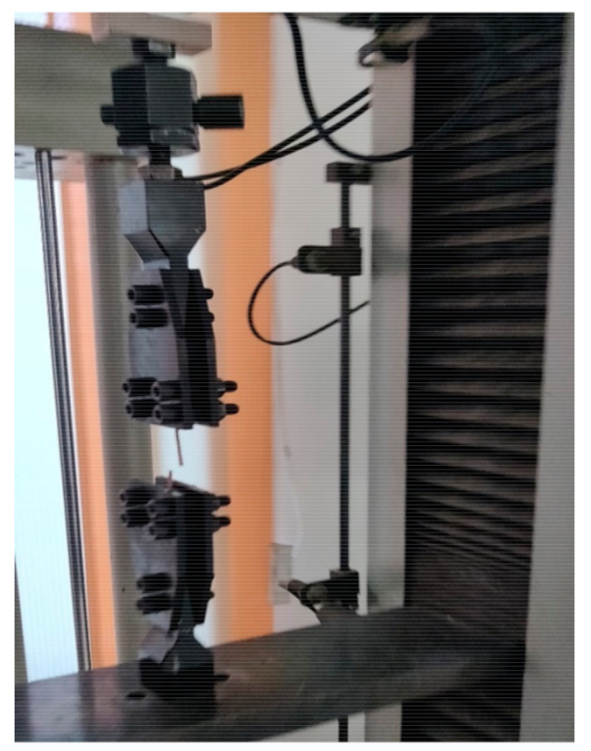

Figure 4. Universal testing machine.

\subsection{FTIR and SEM Testing}

In the present investigation, Fourier transform infrared spectroscopy (FTIR) was used to characterize the composites based upon their bonding behaviour. This can be confirmed 
by the amount of infrared rays absorbed by the solid, liquid, or gas when placed in the spectrometer. The Equations (1)-(5) are used for finding the frequencies $v_{1}$ and $v_{2}$.

$$
\begin{gathered}
d=n \lambda_{1} \text { and } d=(n+1) \lambda_{2} \\
\lambda_{1}=d / n \text { and } \lambda_{2}=d /(n+1) \\
v_{1}=1 / \lambda_{1} \text { and } v_{2}=1 / \lambda_{2} \\
v_{1}=n / d \text { and } v_{2}=(n+1) / d \\
v_{2}-v_{1}=1 / d
\end{gathered}
$$

where: $d$ represents the path differences,

$\lambda_{1}$ and $\lambda_{2}$ represents the wavelengths,

$n$ and $(n+1)$ shows the cycles,

And $v_{1}$ and $v_{2}$ represent the frequencies.

The frequency of the spectrum ranges from $550 \mathrm{~cm}^{-1}$ to $4000 \mathrm{~cm}^{-1}$. These frequency spectrums are divided into five different stages, which are classified as: (i) $2800-4000 \mathrm{~cm}^{-1}$ (ii) $2000-2500 \mathrm{~cm}^{-1}$, (iii) $1500-2000 \mathrm{~cm}^{-1}$, (iv) $1000-1500 \mathrm{~cm}^{-1}$, and (v) $550-1000 \mathrm{~cm}^{-1}$. Fundamentally, the FTIR shows the functional group in the form of peaks produced on the graphs. The frequency ranges from $2800-4000 \mathrm{~cm}^{-1}$, forming the bonds like $\mathrm{C}-\mathrm{H}, \mathrm{N}-\mathrm{H}$, and $\mathrm{O}-\mathrm{H}$ having the spectrums $\mathrm{sp}^{3}, \mathrm{sp}^{2}$, and $\mathrm{sp}$ respectively. The $\mathrm{sp}^{3}$ spectrum has the frequency of $2850 \mathrm{~cm}^{-1}, \mathrm{sp}^{2}$ having the frequency of $3000 \mathrm{~cm}^{-1}$, whereas the frequency of $\mathrm{sp}$ is $3100 \mathrm{~cm}^{-1}$. So, it means the value increases while moving from $\mathrm{sp}^{3}$ towards $\mathrm{sp}$. Now, in the second stage, the frequency varies from $2000-2500 \mathrm{~cm}^{-1}$. In this range, $\mathrm{C} \equiv \mathrm{N}$ bond forms at the frequency of $2250 \mathrm{~cm}^{-1}, \mathrm{C} \equiv \mathrm{C}$ bond forms at the frequency of $2100 \mathrm{~cm}^{-1}$, and $\mathrm{C}=\mathrm{C}=\mathrm{C}$ bond forms at the frequency of $2150 \mathrm{~cm}^{-1}$. The frequency inbetween the $1500-2000 \mathrm{~cm}^{-1}$ in which $C=C$ varies from $1400-1500 \mathrm{~cm}^{-1}, C=N$ varies from $1500-1600 \mathrm{~cm}^{-1}$, and $C=O$ has a frequency in the range of $1680-1810 \mathrm{~cm}^{-1}$. In between the frequencies from $1000-1500 \mathrm{~cm}^{-1} \mathrm{C}-\mathrm{C}, \mathrm{C}-\mathrm{N}, \mathrm{C}-\mathrm{O}$ exists, whereas from $550-1000 \mathrm{~cm}^{-1}$ $\mathrm{C}-\mathrm{I}, \mathrm{C}-\mathrm{Br}$ and $\mathrm{C}-\mathrm{Cl}$ exist [32]. In the present experiment, the infrared spectrum absorption or emission on different compositions of filaments was evaluated on Fourier-transform infrared spectroscopy (FTIR) machine supplied by PerkinElmer Inc., Waltham, MA, USA (Model: PerkinElmer spectrum 2).

Scanning Electron Microscope (SEM) was utilized to visualize the surface and fracture behavior of composites. SEM is a medium for visualizing micro and nano-sized details by impinging a high-energy electron beam on the material surface [33]. The SEM apparatus was supplied by Jeol Ltd., Tokyo, Japan (Model: IT500) having high vacuum and low vacuum resolutions, with Filament Electron gun, and 10-650 Pa Pressure adjustment.

\subsection{Electrical and Thermal Conductivity Testing}

The electrical conductivity testing was performed using insulation resistance tester (Model: S1-522/2) supplied by Megger Ltd., Dover, Kent, United Kingdom having a range of $50 \mathrm{~V}$ to $5000 \mathrm{~V}$ (see Figure 5). This instrument has provision to alter voltage and current loops, allowing accurate measurement of resistance regardless of the voltage applied. Since this method is relatively simple, it does not destruct the samples. In the present research work, the resistivity for different compositions was tested with Megger tester from which the conductivity was measured by using the relationship between resistivity and conductivity. The relations between resistance $(\mathrm{R})$, electrical resistivity $(\rho)$, and conductivity $(\sigma)$ are shown by Equations (6) and (7).

$$
\begin{gathered}
\rho=\mathrm{R} \times \text { Area } / \text { Length } \\
\sigma=1 / \rho
\end{gathered}
$$




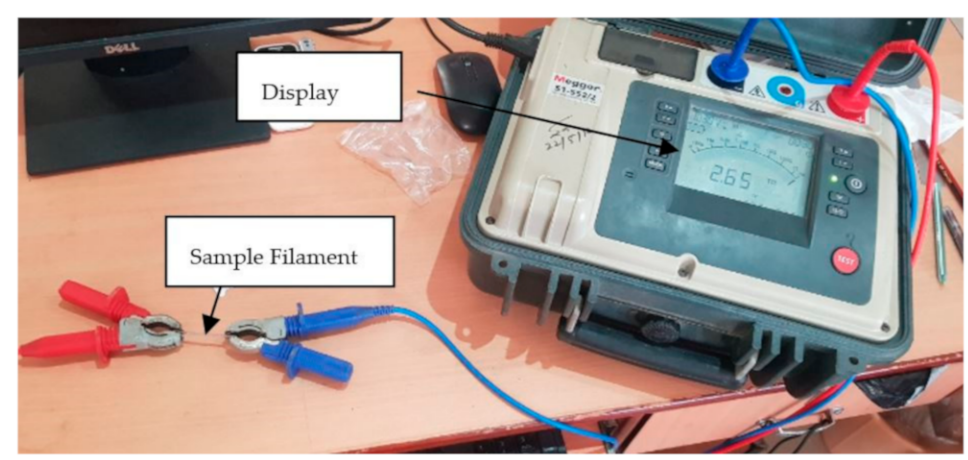

Figure 5. Electrical resistivity testing apparatus.

Thermal conductivity was calculated by the Lee's Disc method [34]. In Lee's Disc Method, the sample is placed in-between two brass discs and maintained at temperature T1 and T2 as shown in Figure 6. A steam chamber with intake and exit ports is placed above the discs. It also has circular holes for thermocouple insertion, which helps to describe a material's ability to conduct the heat. A steady state is quickly obtained while steam is passing through vessel, which is in cylindrical shape. Heat carried through the testing sample is equivalent to heat emitted from the Lee's disc at steady state. Finally, thermal conductivity is measures using Equation (8).

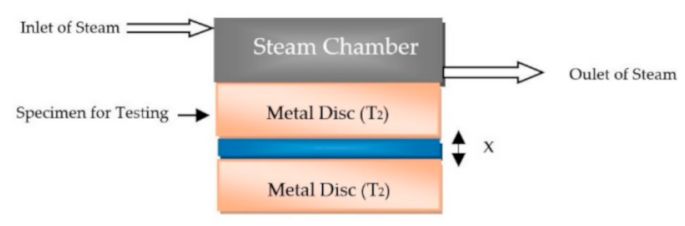

(a)

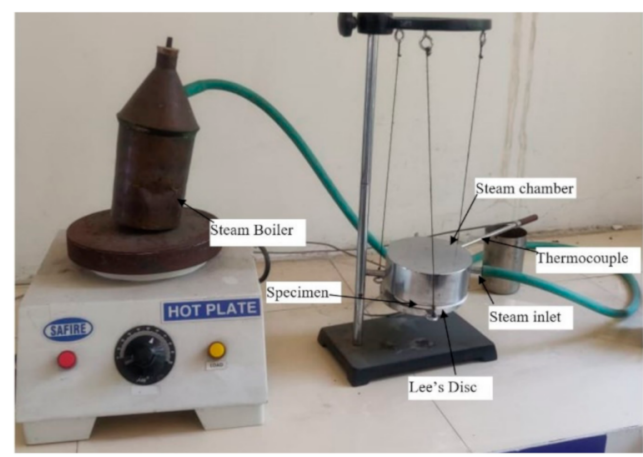

(b)

Figure 6. (a) Thermal conductivity measurement principle; (b) Lee's Disc Experimental Setup.

$$
\mathrm{K}=\frac{\mathrm{mC}\left(\frac{\mathrm{dT}}{\mathrm{dt}}\right) X}{\mathrm{~A}\left(\mathrm{~T}_{2}-\mathrm{T}_{1}\right)}
$$

$\mathrm{K}=$ Thermal conductivity of the specimen

$\mathrm{A}=$ Cross sectional area,

$\mathrm{T}_{2}-\mathrm{T}_{1}=$ Temperature difference across the specimen.

$\mathrm{X}=$ Thickness of the specimen

$\mathrm{m}=$ mass of disc

$\mathrm{C}=$ Specific heat of disc (for brass $-376 \mathrm{~J} / \mathrm{kg}{ }^{\circ} \mathrm{C}$ )

$\mathrm{dT} / \mathrm{dt}=$ difference in temperature w.r.t time

\section{Results and Discussion}

\subsection{Melt Flow Properties}

During melt flow testing, significant variation in fluidity was experienced due to particle size and concentration. Initially, nylon 6 material was mixed separately with $A, B$, $C$ sized copper particles at different proportions to check the melt flow rate of particular compositions. Firstly, $A$ was mixed with the nylon 6 material in three different proportions i.e., $1 \%, 2.5 \%$ and $5 \%$, which gave composition $A 1, A 2$ and $A 3$. By using the weighing 
machine, particles were mixed and then three readings of melt flow rate were taken using MIM by putting $2.180 \mathrm{~kg}$ weight at $220^{\circ} \mathrm{C}$, and the mean value of melt flow rate was finally considered. The results show that with an increase in the quantity 100 mesh copper particles in the nylon 6 materials, the melt flow rate was decreasing continuously. Similarly, the composition with $B$ and $C$ particles with nylon 6 material at different ratios was prepared. The data collected during this experiment are shown in Table 3 in which the mean and standard deviation values were retrieved for each combination. It was observed that the standard deviation of all the composites was different, which occurs due to difference in mean values for each experiment.

It can be noted that an increase in the concentration of reinforcements in Nylon6 decreased the MFI of polymer composites irrespective of copper particle size. This is attributed to the reduced fluidity of the polymer matrix due to the addition of metal particles. The polymer granules and metal particles were not properly attached, and there was a lack of proper bonding between polymer and metal.

Table 3. MFI of nylon 6 reinforced with copper particles.

\begin{tabular}{|c|c|c|c|c|c|}
\hline Material Composition & 1st Reading & 2nd Reading & 3rd Reading & Mean & $\begin{array}{l}\text { Standard } \\
\text { Deviation }\end{array}$ \\
\hline \multicolumn{6}{|c|}{$A$ Copper particles with nylon 6 (gm/10 min) } \\
\hline$A 1$ & 7.41 & 6.175 & 6.536 & 6.707 & 0.635 \\
\hline$A 2$ & 5.905 & 5.445 & 6.725 & 6.025 & 0.648 \\
\hline A3 & 4.54 & 4.57 & 4.055 & 4.388 & 0.289 \\
\hline \multicolumn{6}{|c|}{$B$ Copper particles with nylon 6 (gm/10 min) } \\
\hline B1 & 4.11 & 4.732 & 4.526 & 4.456 & 0.316 \\
\hline$B 2$ & 3.805 & 4.695 & 4.126 & 4.208 & 0.450 \\
\hline B3 & 2.515 & 1.675 & 1.985 & 2.058 & 0.424 \\
\hline \multicolumn{6}{|c|}{ C Copper particles with nylon 6 (gm/10 min) } \\
\hline C1 & 9.28 & 7.315 & 8.225 & 8.273 & 0.983 \\
\hline C2 & 5.795 & 5.738 & 5.765 & 5.766 & 0.028 \\
\hline C3 & 3.68 & 3.76 & 3.65 & 3.696 & 0.056 \\
\hline
\end{tabular}

\subsubsection{Composition of ABS with Single Copper Particles}

ABS material was mixed with copper particles at different proportions to check the flow rate at every stage by using the $2.180 \mathrm{~kg}$ ram weight and $220{ }^{\circ} \mathrm{C}$ temperature of MIM. In the first place, $1 \% A$ (Copper) and $99 \%$ (ABS) named as $A 4$ were mixed together to investigate the mean flow rate, which was calculated as $2.243 \mathrm{gm} / 10 \mathrm{~min}$. Similarly, the mixtures $A 5$ and $A 6$ were prepared. While increasing the copper particles in ABS, the melt flow rate was decreasing as experienced in the case of Nylon6.

In the second place, $B 4$ was prepared using the weighing machine after which the melt flow rate was calculated as $1.881 \mathrm{gm} / 10 \mathrm{~min}$. This was followed by the preparation and testing of $B 4, B 5, B 6, B 7$, and $B 8$ compositions. It was noticed that the melt flow rate was increasing from $1 \%$ to $5 \%$, but afterwards, with further addition of 200 mesh copper particles, the melt flow rate was decreasing.

Thirdly, when C4 compositions were prepared and tested, it was observed that as the percentage of copper particles was increased, the melt flow rate also increased, which was not experienced in previous compositions of both ABS and Nylon6. The ABS mixed with 400 mesh size copper was smoothly extruded out from the nozzle due to higher fluidity rate. It was examined that the fluidity increases while increasing the copper percentage, which means the intermixing capacity is better for 400 mesh Copper particles with ABS. Thus, while increasing the 400 mesh copper particles in ABS, the melt flow rate correspondingly increases. The size of these particles is appropriate for ABS molecules to attach and form a uniform mixture. All the detailed readings are displayed in Table 4 in which mean and 
standard deviation value are discussed, and where it is shown that the most deviated value was of $B 5$ composition, whereas the least deviated value was of $B 7$ composition. This also occurs due to difference in mean values of all the compositions.

Table 4. MFI of ABS reinforced with single particle size copper.

\begin{tabular}{|c|c|c|c|c|c|}
\hline Material Composition & 1st Reading & 2nd Reading & 3rd Reading & Mean & Standard Dev. \\
\hline \multicolumn{6}{|c|}{ A Copper particles with ABS (gm/10 min) } \\
\hline$A 4$ & 2.17 & 2.24 & 2.32 & 2.243 & 0.075 \\
\hline A5 & 1.565 & 1.785 & 1.68 & 1.676 & 0.110 \\
\hline$A 6$ & 1.47 & 1.61 & 1.715 & 1.598 & 0.122 \\
\hline \multicolumn{6}{|c|}{$B$ Copper particles with ABS (gm/10 min) } \\
\hline$B 4$ & 1.715 & 1.79 & 2.138 & 1.881 & 0.225 \\
\hline B5 & 2.48 & 2.17 & 2.03 & 2.226 & 0.23 \\
\hline$B 6$ & 2.64 & 2.35 & 2.38 & 2.456 & 0.159 \\
\hline B7 & 2.385 & 2.46 & 2.32 & 2.388 & 0.070 \\
\hline$B 8$ & 2.29 & 2.365 & 2.22 & 2.291 & 0.072 \\
\hline \multicolumn{6}{|c|}{ C Copper particles with ABS (gm/10 min) } \\
\hline C4 & 1.475 & 1.635 & 1.65 & 1.586 & 0.096 \\
\hline C5 & 1.575 & 1.755 & 1.68 & 1.67 & 0.090 \\
\hline C6 & 2.115 & 1.715 & 1.905 & 1.911 & 0.200 \\
\hline
\end{tabular}

\subsubsection{Composition of ABS with Double Particle Size}

The double copper particle means equal mixing of two different-sized copper particles in the polymer material. Furthermore, Nylon6 was not used to prepare double copper size compositions as MFI was severely reduced in previous studies. The reduced MFI of filaments would not be beneficial for 3D printing applications. Firstly, in this experimental work, mixing of $1 \%(A$ and $B)$ of equal proportion with $99 \%$ ABS was done. The mean value of melt flow rate of $(A+B) 4$ was obtained as $2.42 \mathrm{gm} / 10 \mathrm{~min}$. After that, the mean value of melt flow rate of $(A+B) 9$ and $(A+B) 10$ was $2.34 \mathrm{gm} / 10 \mathrm{~min}$ and $2.27 \mathrm{gm} / 10 \mathrm{~min}$ respectively. So, it was observed that the melt flow rate was decreasing while increasing the mixture of 100 and 200 mesh copper particles with ABS.

The mean values of MFI of $(B+C) 4,(B+C) 9$, and $(B+C) 10$ were $1.99 \mathrm{gm} / 10 \mathrm{~min}$, $1.7 \mathrm{gm} / 10 \mathrm{~min}$, and $2.25 \mathrm{gm} / 10 \mathrm{~min}$ respectively. From these results, it was deduced that the melt flow rate was decreasing up to $3 \%$ loading of 200 and 400 mesh copper particles. However, with the further addition of double-sized particles, there was an abrupt increase in MFI, which indicates that 400 mesh copper particles help to increase the fluidity.

After testing of $(A+C) 4,(A+C) 9$, and $(A+C) 10$ mixtures, it was found that while increasing the $(A$ and $C)$ particles concentration ratios in ABS, the melt flow rate also increased. The combination of 100 mesh with 400 mesh copper particles improved the fluidity of the mixture. The detailed measurements of MFI of double particle size-reinforced ABS are shown in Table 5. 
Table 5. MFI of ABS reinforced with double particle size copper.

\begin{tabular}{|c|c|c|c|c|c|}
\hline Material Composition & 1st Reading & 2nd Reading & 3rd Reading & Mean & Standard Dev. \\
\hline \multicolumn{6}{|c|}{$A+B$ Copper particles with ABS (gm/10 min) } \\
\hline$(A+B) 4$ & 2.45 & 2.405 & 2.41 & 2.421 & 0.024 \\
\hline$(A+B) 9$ & 2.32 & 2.325 & 2.38 & 2.341 & 0.033 \\
\hline$(A+B) 10$ & 2.245 & 2.325 & 2.26 & 2.276 & 0.042 \\
\hline \multicolumn{6}{|c|}{$B+C$ Copper particles with ABS (gm/10 min) } \\
\hline$(B+C) 4$ & 2.075 & 1.885 & 2.03 & 1.996 & 0.099 \\
\hline$(B+C) 9$ & 1.68 & 1.775 & 1.648 & 1.701 & 0.066 \\
\hline$(B+C) 10$ & 2.27 & 2.245 & 2.25 & 2.255 & 0.013 \\
\hline \multicolumn{6}{|c|}{$A+C$ Copper particles with ABS (gm/10 min) } \\
\hline$(A+C) 4$ & 1.935 & 1.735 & 2.305 & 1.991 & 0.289 \\
\hline$(A+C) 9$ & 2.09 & 2.085 & 1.825 & 2 & 0.151 \\
\hline$(A+C) 10$ & 2.265 & 2.375 & 2.29 & 2.31 & 0.057 \\
\hline
\end{tabular}

\subsubsection{Composition of ABS and Nylon 6 with Triple Particle Size}

In this experimental study, three different sizes of copper particles were mixed in equal proportions with $\mathrm{ABS}$ and nylon 6 to check the melt flow rate. The mean value of melt flow rate of $(A+B+C) 11$ was $18.25 \mathrm{gm} / 10 \mathrm{~min}$. Furthermore, the mean values of MFI for $(A+B+C) 12$ and $(A+B+C) 13$ were $28.27 \mathrm{gm} / 10 \mathrm{~min}$ and $30.73 \mathrm{gm} / 10 \mathrm{~min}$ respectively. It can be noticed from the above mean values that melt flow rate was increasing while increasing the mixture of $(A, B$ and $C)$ copper particles with nylon 6 .

Furthermore, the testing of triple-sized copper particles mixed with ABS revealed a similar scenario. The mean values of MFI of compositions $(A+B+C) 9,(A+B+C) 10$, and $(A+B+C)$ were measured as $1.885 \mathrm{gm} / 10 \mathrm{~min}, 2.28 \mathrm{gm} / 10 \mathrm{~min}, 2.45 \mathrm{gm} / 10 \mathrm{~min}$ respectively. So, from the above discussion, it was observed that while increasing the mixture of $(A, B$, and $C)$ copper particles with $\mathrm{ABS}$, the melt flow rate was also increased. Table 6 shows the full description of values obtained during experimentation in which the mean value and standard deviation values are displayed. From the standard deviation value, the most dispersed value was obtained in $(A+B+C) 11$ material composition while the least dispersed value was obtained at $(A+B+C) 10$ composite material. The efficacy of 400 mesh-sized copper particles is highlighted by these investigations. The smaller size of copper reinforcements showed better adherence and mixing with thermoplastic materials [35]. This resulted in ease of flow during the molten state, which further improved the MFI.

Table 6. MFI of ABS and nylon 6 with triple particle size copper.

\begin{tabular}{cccccc}
\hline Material Composition & 1st Reading & 2nd Reading & 3rd Reading & Mean & Standard Dev. \\
\hline \multicolumn{7}{c}{ Mixture of $A, B$ and $C$ copper particles with nylon $6(\mathrm{gm} / 10 \mathrm{~min})$} \\
\hline$(A+B+C) 11$ & 19.975 & 18.515 & 16.285 & 18.258 & 28.27 \\
$(A+B+C) 12$ & 30.25 & 26.65 & 27.91 & 30.73 & 1.858 \\
$(A+B+C) 13$ & 31.76 & 29.90 & 30.55 & 0.943 \\
\hline$(A+B+C) 9$ & Mixture of $A, B$ and $C$ copper particles with ABS (gm/10 min) \\
$(A+B+C) 10$ & 1.785 & 1.865 & 2.005 & 1.885 & 0.111 \\
$(A+B+C) 14$ & 2.245 & 2.31 & 2.285 & 2.28 & 0.032 \\
\hline
\end{tabular}

The Scanning Electron Microscope (SEM) images of composites having different ratios of copper particles with ABS are shown in Figure 7. 


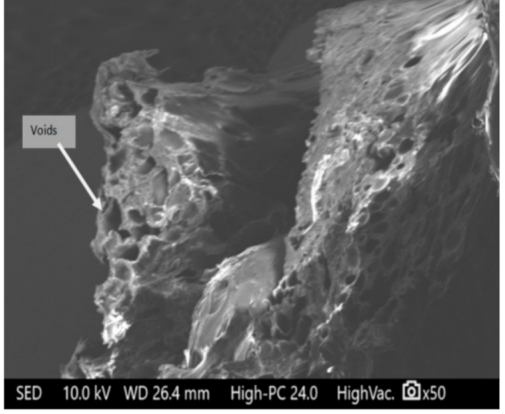

(a)

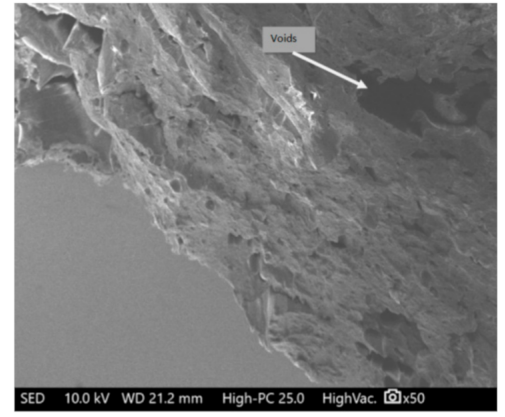

(b)

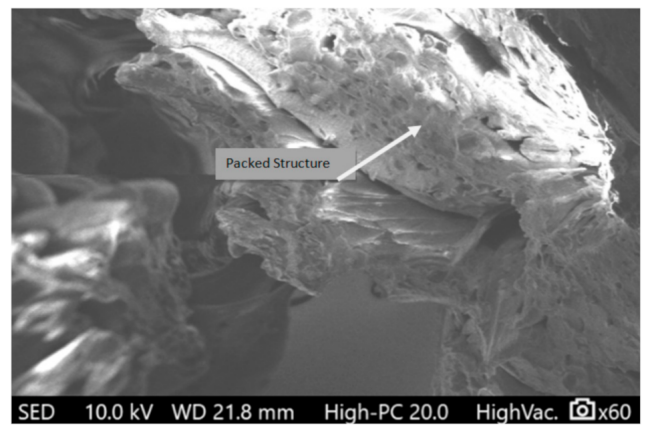

(c)

Figure 7. SEM images of (a) B5, (b) B6, and (c) B8.

The SEM images in Figure 7a represents large voids in the case of composites with 2.5\% copper particles with $97.5 \%$ ABS, while Figure $7 \mathrm{~b}$ represents the lesser voids as copper concentration was increased to $5 \%$. Furthermore, in Figure $7 c$, the packed structure having $8 \%$ copper particles is visualized. This indicates that with an increase in the quantity of copper particles in ABS polymers, there is continuous reduction of voids and porosity in the structure. This reduction in voids improved the flow rate of composite material, and hence it can be deduced that a higher concentration of copper particles with smaller particle size is suitable for $3 \mathrm{~d}$ printer.

\subsection{Tensile Properties}

After the melt flow rate testing of different composite materials, the tensile testing of extruded filaments with different compositions was performed for comparison. The length and diameter of the filaments were fixed as $90 \mathrm{~mm}$ and $1.75 \mathrm{~mm}$ respectively for the tensile testing for uniformity. In this tensile testing process, the peak load $(\mathrm{N})$, peak elongation $(\mathrm{mm})$, break load $(\mathrm{N})$, break elongation $(\mathrm{mm})$, strength at peak $(\mathrm{MPa})$, strength at break (MPa), \% elongation at peak, \% elongation at break, Young's modulus, and Poisson's ratio were calculated [36]. The tensile testing was done only for ABS as filaments prepared with Nylon6 were not found suitable for 3D printing applications. ASTM D4018-17 is a standard testing technique used for testing tensile properties of composite filaments with diameter $1.75 \mathrm{~mm}$ and length $90 \mathrm{~mm}$.

\subsubsection{Tensile Testing of Single Copper Particle with ABS}

First of all, the Tensile Testing was done for the filaments that have the composition of $A 4, A 9$, and $A 10$. It was concluded that tensile properties were maximum for the composition with $3 \%$ copper particles, whereas the strength at peak was maximum for the composition having 6\% reinforcements. On the other hand, the maximum strength at break was achieved in case of composition $A 4$. It was concluded that the ultimate tensile strength was increasing while the percentage of $A$ Copper particles was added up to $3 \%$. After that, there was a sudden drop in ultimate tensile strength with further addition of 100 mesh copper particles in ABS. The whole data is shown in tabular form in Table 7. Also, 
the stress-strain graphs are displayed in Figure 8a-c. Tensile testing was done on multiple specimens for a particular composition, which is represented in each figure.

Table 7. Tensile testing of $A$ copper and ABS at different proportions.

\begin{tabular}{|c|c|c|c|c|c|c|c|c|c|c|}
\hline $\begin{array}{l}\text { Material } \\
\text { Composition }\end{array}$ & $\begin{array}{l}\text { Peak } \\
\text { Load } \\
(\mathrm{N})\end{array}$ & $\begin{array}{c}\text { Peak } \\
\text { Elongation } \\
(\mathrm{mm})\end{array}$ & $\begin{array}{c}\text { Break } \\
\text { Load } \\
(\mathrm{N})\end{array}$ & $\begin{array}{c}\text { Break } \\
\text { Elongation } \\
(\mathrm{mm})\end{array}$ & $\begin{array}{l}\text { Strengthat } \\
\text { Peak } \\
\text { (MPa) }\end{array}$ & $\begin{array}{l}\text { Strengthat } \\
\text { Break } \\
\text { (MPa) }\end{array}$ & $\begin{array}{c}\text { Elongation } \\
\text { at Peak } \\
(\%)\end{array}$ & $\begin{array}{l}\text { Elongation } \\
\text { at Break } \\
\quad(\%)\end{array}$ & $\begin{array}{l}\text { Young's } \\
\text { Modu- } \\
\text { lus } \\
\text { (MPa) }\end{array}$ & $\begin{array}{l}\text { Poisson's } \\
\text { Ratio }\end{array}$ \\
\hline$A 4$ & 135.93 & 2.72 & 122.34 & 3.2 & 43.3 & 51.1 & 4.3 & 5.3 & 795.753 & 1.6352 \\
\hline A9 & 149.83 & 3.10 & 134.85 & 3.6 & 47.7 & 42.9 & 5.0 & 6.3 & 769.354 & 1.5444 \\
\hline A10 & 112.43 & 2.53 & 101.19 & 2.8 & 49.7 & 44.7 & 4.3 & 4.7 & 982.212 & 1.2566 \\
\hline
\end{tabular}

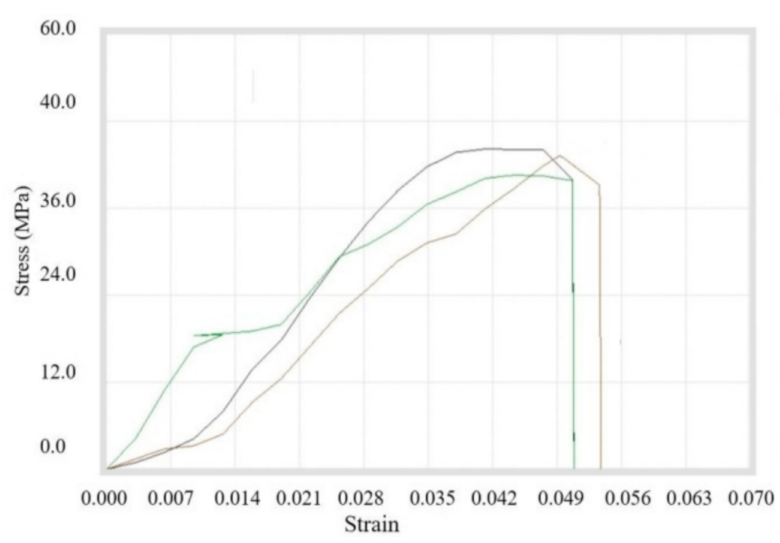

(a)

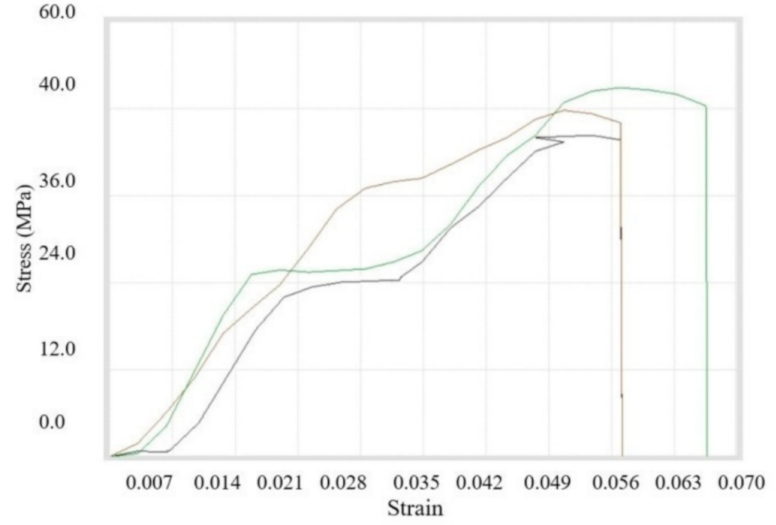

(b)

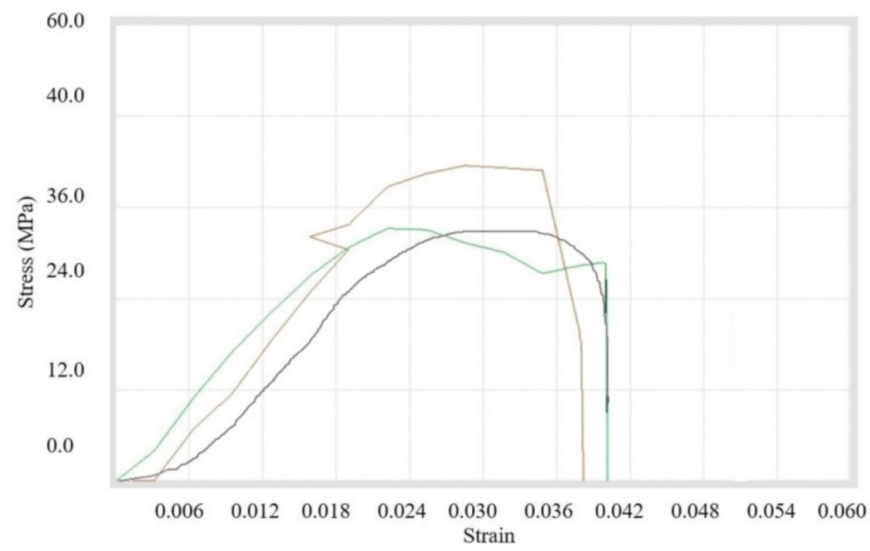

(c)

Figure 8. Stress-strain curves for (a) A4, (b) A9, and (c) A10 filament samples.

Secondly, the tensile testing was done for the compositions $B 4, B 9, B 10, B 7$, and $B 8$, which were prepared using 200 mesh copper particles. It was found that the maximum values of tensile properties were obtained for the composition of $8 \%$ copper and $92 \%$ ABS. The maximum value of percentage elongation at break was reached during the composition of $10 \%$ copper, while the break elongation was maximum for $1 \%$ reinforcement. It was concluded that the ultimate tensile strength was decreasing continuously while increasing the percentage of copper particles with ABS, but it was maximum at $8 \%$ concentration. 
Table 8 shows the overall readings and stress-strain diagram for overall compositions in Figure 9a-e.

Table 8. Tensile testing of $B$ copper and ABS at different proportions.

\begin{tabular}{|c|c|c|c|c|c|c|c|c|c|c|}
\hline $\begin{array}{c}\text { Material } \\
\text { Composition }\end{array}$ & $\begin{array}{c}\text { Peak } \\
\text { Load } \\
(\mathrm{N})\end{array}$ & $\begin{array}{c}\text { Peak } \\
\text { Elongation } \\
(\mathrm{mm})\end{array}$ & $\begin{array}{c}\text { Break } \\
\text { Load } \\
(\mathrm{N})\end{array}$ & $\begin{array}{c}\text { Break } \\
\text { Elongation } \\
(\mathrm{mm})\end{array}$ & $\begin{array}{c}\text { Strength } \\
\text { at Peak } \\
\text { (MPa) }\end{array}$ & $\begin{array}{c}\text { Strength } \\
\text { at Break } \\
\text { (MPa) }\end{array}$ & $\begin{array}{c}\text { Elongation } \\
\text { at Peak } \\
(\%)\end{array}$ & $\begin{array}{c}\text { Elongation } \\
\text { at Break } \\
(\%)\end{array}$ & $\begin{array}{c}\text { Young's } \\
\text { Modulus } \\
\text { (MPa) }\end{array}$ & $\begin{array}{c}\text { Poisson's } \\
\text { Ratio }\end{array}$ \\
\hline$B 4$ & 145.10 & 2.34 & 130.59 & 3.3 & 46.2 & 41.6 & 4.0 & 5.3 & 987.179 & 1.372 \\
\hline B9 & 134.97 & 2.66 & 121.47 & 3.2 & 43.0 & 38.7 & 4.7 & 5.0 & 808.270 & 1.238 \\
\hline B10 & 126.47 & 2.47 & 113.82 & 2.7 & 40.3 & 36.2 & 4.0 & 4.3 & 815.789 & 0.977 \\
\hline$B 7$ & 155.90 & 2.95 & 140.31 & 3.23 & 49.65 & 44.685 & 5 & 5 & 841.525 & 1.443 \\
\hline B8 & 110.30 & 3.04 & 99.27 & 3.135 & 35.13 & 31.615 & 5 & 5.5 & 577.796 & 0.991 \\
\hline
\end{tabular}

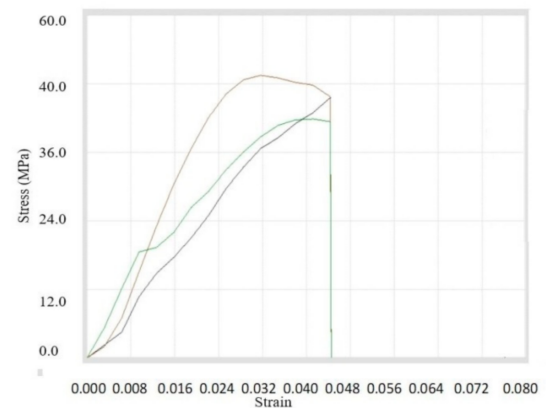

(a)

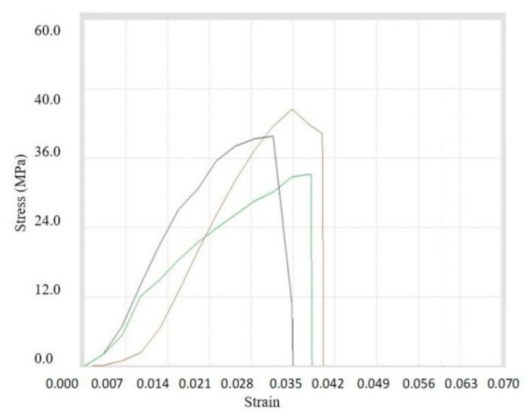

(c)

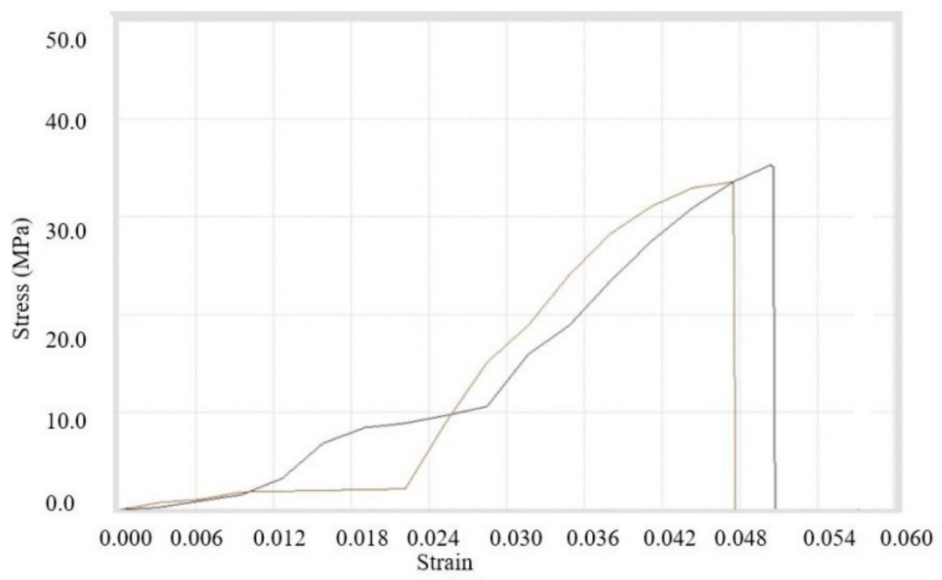

(e)

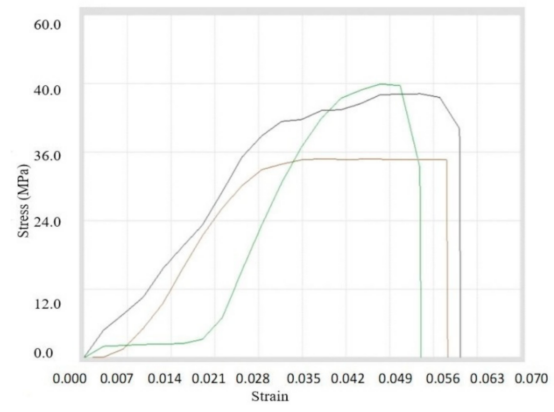

(b)

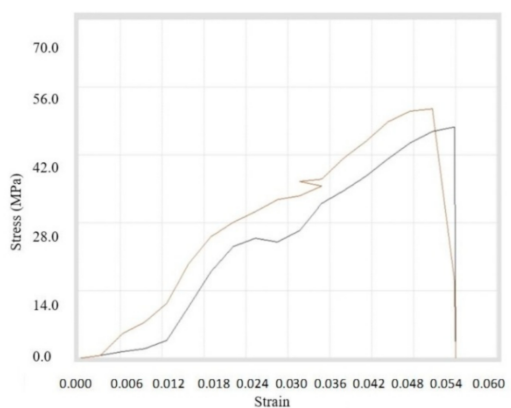

(d)

Figure 9. Stress-strain curves for (a) B4, (b) B9, (c) B10, (d) B7, and (e) B8 composite samples. 
Thirdly, the tensile testing was done for the compositions $C 4, C 9$, and $C 10$. It was observed that break elongation was maximum for $1 \%$ copper particles, whereas the peak load, break load, strength at peak, and strength at break were highest for $3 \%$ copper particles. However, the peak elongation and elongation at peak were maximum for the composition of $6 \%$ copper particles. It was observed that the ultimate tensile strength was maximum for composition 3\% reinforcement while ultimate tensile strength was nearly the same for $1 \%$ and $6 \%$ compositions. All of the information is tabulated in Table 9 and the stress-strain curves shown in Figure 10a-c.

Table 9. Tensile testing of $C$ copper and ABS at different proportions.

\begin{tabular}{|c|c|c|c|c|c|c|c|c|c|c|}
\hline $\begin{array}{c}\text { Material } \\
\text { Composition }\end{array}$ & $\begin{array}{c}\text { Peak } \\
\text { Load } \\
(\mathrm{N})\end{array}$ & $\begin{array}{c}\text { Peak } \\
\text { Elongation } \\
(\mathrm{mm})\end{array}$ & $\begin{array}{c}\text { Break } \\
\text { Load } \\
(\mathrm{N})\end{array}$ & $\begin{array}{c}\text { Break } \\
\text { Elongation } \\
(\mathrm{mm})\end{array}$ & $\begin{array}{l}\text { Strength } \\
\text { at Peak } \\
(\mathrm{MPa})\end{array}$ & $\begin{array}{l}\text { Strengthat } \\
\text { Break } \\
\text { (MPa) }\end{array}$ & $\begin{array}{c}\text { Elongation } \\
\text { at Peak } \\
(\%)\end{array}$ & $\begin{array}{c}\text { Elongation } \\
\text { at Break } \\
(\%)\end{array}$ & $\begin{array}{l}\text { Young's } \\
\text { Modulus } \\
\text { (MPa) }\end{array}$ & $\begin{array}{c}\text { Poisson's } \\
\text { Ratio }\end{array}$ \\
\hline$C 4$ & 131.70 & 2.72 & 118.53 & 3.9 & 41.9 & 37.7 & 4.3 & 6.7 & 770.220 & 1.4703 \\
\hline $\mathrm{C} 9$ & 134.67 & 2.34 & 121.20 & 3.3 & 42.9 & 38.6 & 4.0 & 5.3 & 916.666 & 1.2738 \\
\hline C10 & 131.03 & 2.91 & 117.93 & 3.8 & 41.7 & 37.6 & 4.7 & 6.7 & 716.494 & 1.4288 \\
\hline
\end{tabular}
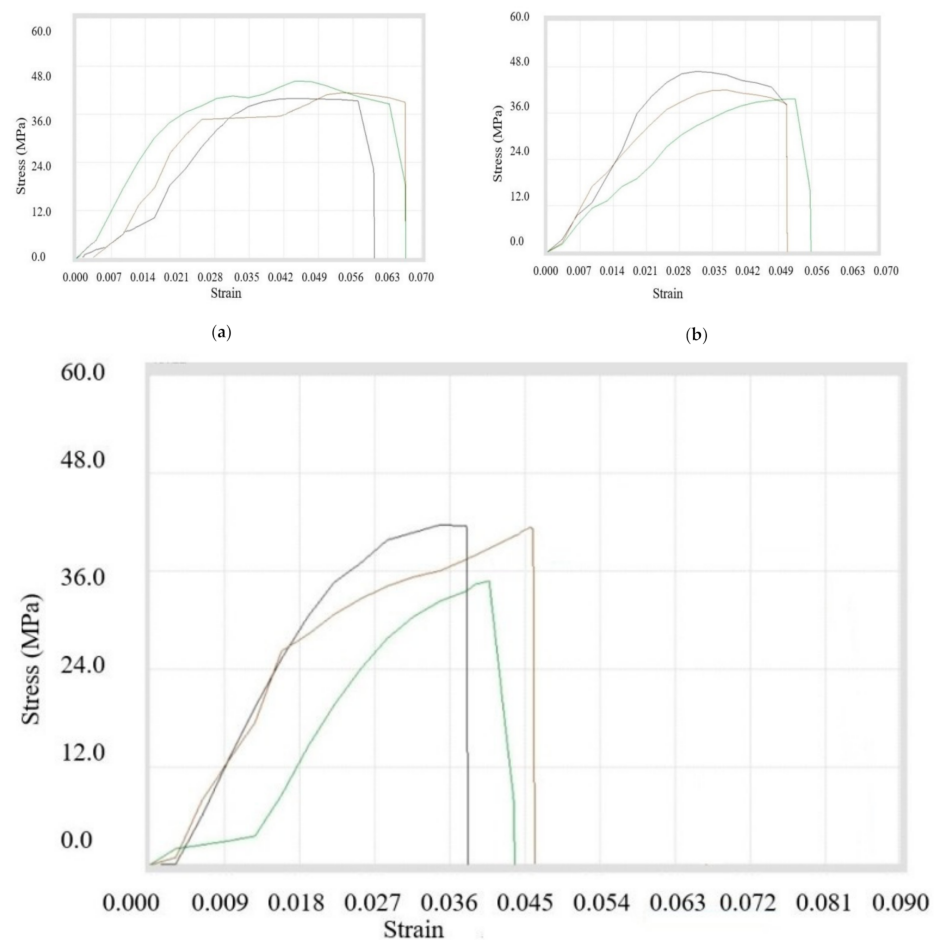

(c)

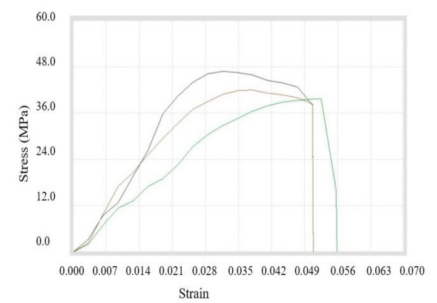

(b) 
in $1 \%$ reinforcement. It must be further noted that the ultimate tensile strength was the same for composites prepared using $1 \%$ and $3 \%$ copper particles. A sudden decrease in ultimate tensile strength was noted while adding more double-sized copper particles ( $A$ and $B$ ) in ABS. Table 10 shows the tensile properties and Figure 11a-c represents the stress-strain curves.

Table 10. Tensile testing of $A+B$ copper and ABS at different proportions.

\begin{tabular}{|c|c|c|c|c|c|c|c|c|c|c|}
\hline $\begin{array}{c}\text { Material } \\
\text { Composition }\end{array}$ & $\begin{array}{c}\text { Peak } \\
\text { Load } \\
(\mathrm{N})\end{array}$ & $\begin{array}{c}\text { Peak } \\
\text { Elongation } \\
(\mathrm{mm})\end{array}$ & $\begin{array}{c}\text { Break } \\
\text { Load } \\
(\mathrm{N})\end{array}$ & $\begin{array}{c}\text { Break } \\
\text { Elongation } \\
(\mathrm{mm})\end{array}$ & $\begin{array}{l}\text { Strength } \\
\text { at Peak } \\
(9 \mathrm{MPa})\end{array}$ & $\begin{array}{c}\text { Strengthat } \\
\text { Break } \\
\text { (MPa) }\end{array}$ & $\begin{array}{c}\text { Elongation } \\
\text { at Peak } \\
(\%)\end{array}$ & $\begin{array}{c}\text { Elongation } \\
\text { at Break } \\
(\%)\end{array}$ & $\begin{array}{c}\text { Young's } \\
\text { Modulus } \\
\text { (MPa) }\end{array}$ & $\begin{array}{c}\text { Poisson's } \\
\text { Ratio }\end{array}$ \\
\hline$(A+B) 4$ & 138.25 & 3.14 & 124.43 & 3.6 & 44.0 & 39.6 & 5.0 & 6.0 & 700.636 & 1.4256 \\
\hline$(A+B) 9$ & 138.95 & 2.95 & 125.06 & 3.1 & 44.3 & 39.8 & 5.1 & 5.0 & 750.847 & 1.2338 \\
\hline$(A+B) 10$ & 118.40 & 2.57 & 106.56 & 2.8 & 37.7 & 33.9 & 4.5 & 4.5 & 733.463 & 0.9492 \\
\hline
\end{tabular}

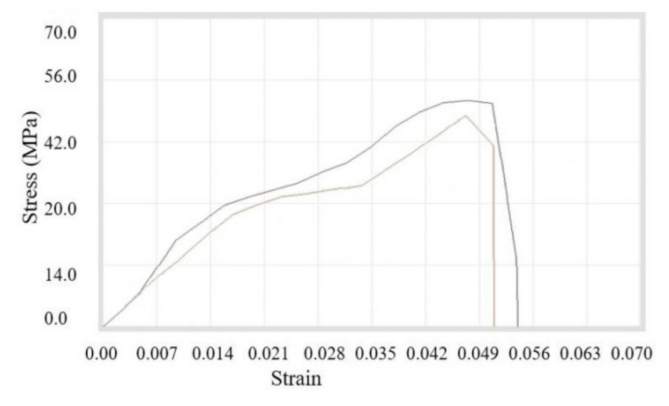

(a)

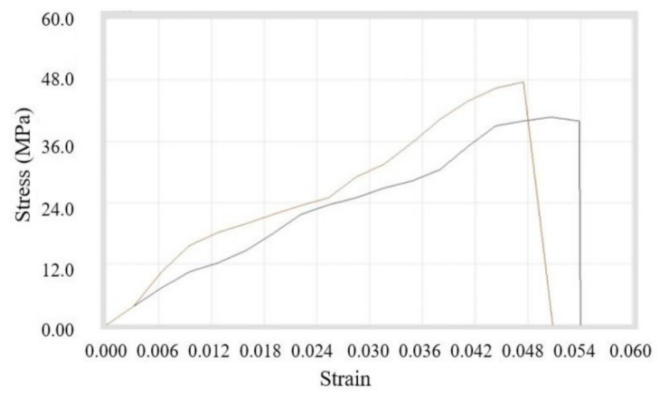

(b)

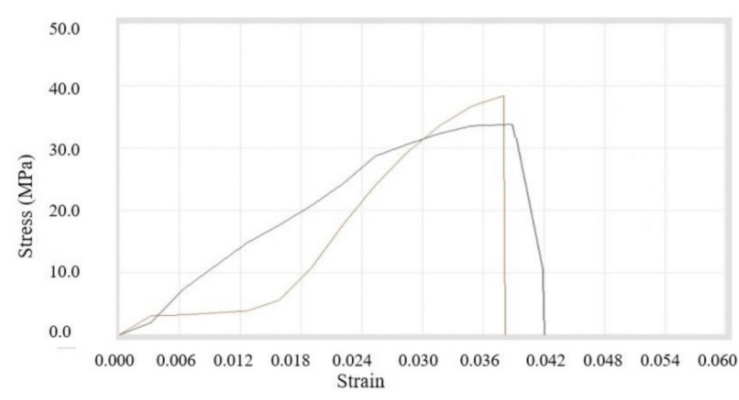

(c)

Figure 11. Stress-strain curves for $(\mathbf{a})(A+B) 4,(\mathbf{b})(A+B) 9,(\mathbf{c})(A+B) 10$ composite samples.

Now, the filaments prepared from $(B+C) 4,(B+C) 9,(B+C) 10$ were tested for comparison. It was experienced that peak load, peak elongation, break load, strength at peak, strength at break, and \% elongation at peak were highest for 3\% addition. Conversely, for $6 \%$ addition, the break elongation and \% elongation at break were maximum. It was inferred that the ultimate tensile strength was lowest for $6 \%$ and maximum for $3 \%$ copper reinforcement. Table 11 shows the exact readings for all compositions and Figure 12a-c shows the stress-strain curves for particular compositions.

Table 11. Tensile testing of $B$ and $C$ and ABS at different proportions.

\begin{tabular}{|c|c|c|c|c|c|c|c|c|c|c|}
\hline $\begin{array}{c}\text { Material } \\
\text { Composition }\end{array}$ & $\begin{array}{l}\text { Peak } \\
\text { Load } \\
(\mathrm{N})\end{array}$ & $\begin{array}{c}\text { Peak } \\
\text { Elongation } \\
(\mathrm{mm})\end{array}$ & $\begin{array}{l}\text { Break } \\
\text { Load } \\
\text { (N) }\end{array}$ & $\begin{array}{c}\text { Break } \\
\text { Elongation } \\
(\mathrm{mm})\end{array}$ & $\begin{array}{l}\text { Strength } \\
\text { at Peak } \\
\text { (9 MPa) }\end{array}$ & $\begin{array}{c}\text { Strength } \\
\text { at Break } \\
\text { (MPa) }\end{array}$ & $\begin{array}{c}\text { Elongation } \\
\text { at Peak } \\
(\%)\end{array}$ & $\begin{array}{c}\text { Elongation } \\
\text { at Break } \\
(\%)\end{array}$ & $\begin{array}{l}\text { Young's } \\
\text { Modulus } \\
\text { (MPa) }\end{array}$ & $\begin{array}{c}\text { Poisson's } \\
\text { Ratio }\end{array}$ \\
\hline$(B+C) 4$ & 128.68 & 2.76 & 115.81 & 2.9 & 41.0 & 36.9 & 4.8 & 4.8 & 742.753 & 1.0701 \\
\hline$(B+C) 9$ & 155.35 & 3.42 & 139.82 & 3.6 & 49.5 & 44.5 & 6.0 & 6.0 & 723.684 & 1.602 \\
\hline$(B+C) 10$ & 122.05 & 3.42 & 109.85 & 3.9 & 38.9 & 35.0 & 6.0 & 6.5 & 568.713 & 1.365 \\
\hline
\end{tabular}




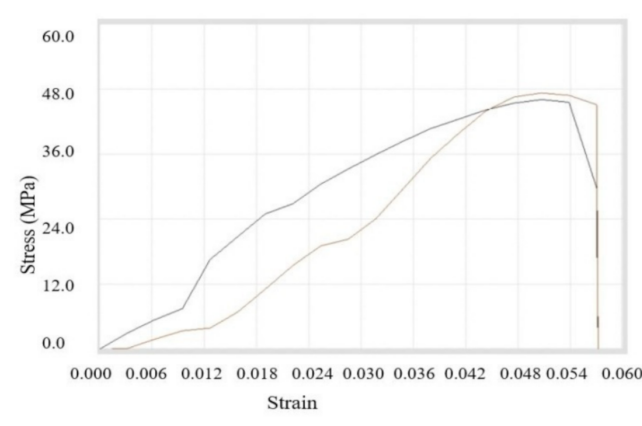

(a)

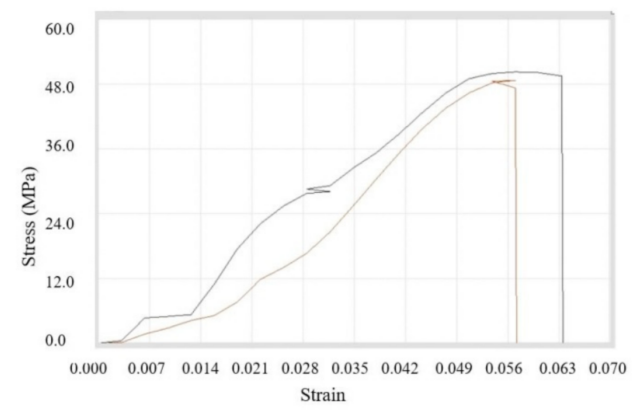

(b)

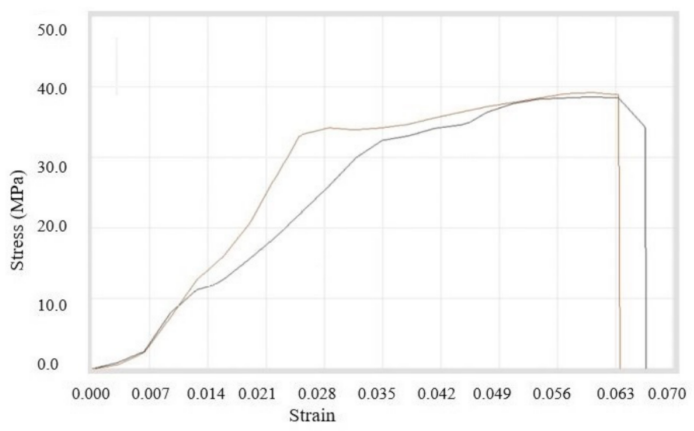

(c)

Figure 12. Stress-strain curves for $(\mathbf{a})(B+C) 4,(\mathbf{b})(B+C) 9,(\mathbf{c})(B+C) 10$ composite samples.

Thirdly, the double-sized compositions of $(A+C) 4,(A+C) 9$, and $(B+C)$ were prepared and filaments were used for testing. It was observed that peak load, peak elongation, break load, break elongation, strength at peak, strength at break, \% elongation at peak, and \% elongation at break were maximum for the composition of the $1 \%$ copper. It can be further noted that the ultimate tensile strength was decreasing continuously with the addition of double-size copper particles (100 and 400 mesh) in ABS. All of the data in tabulated form is shown in Table 12 with stress-strain curves in Figure 13a-c.

Table 12. Tensile testing of $A$ and $C$ copper and ABS at different proportions.

\begin{tabular}{|c|c|c|c|c|c|c|c|c|c|c|}
\hline $\begin{array}{c}\text { Material } \\
\text { Composition }\end{array}$ & $\begin{array}{c}\text { Peak } \\
\text { Load } \\
(\mathrm{N})\end{array}$ & $\begin{array}{l}\text { Peak } \\
\text { Elongation } \\
(\mathrm{mm})\end{array}$ & $\begin{array}{c}\text { Break } \\
\text { Load } \\
(\mathbf{N})\end{array}$ & $\begin{array}{c}\text { Break } \\
\text { Elongation } \\
(\mathrm{mm})\end{array}$ & $\begin{array}{c}\text { Strengthat } \\
\text { Peak } \\
\text { (MPa) }\end{array}$ & $\begin{array}{l}\text { Strengthat } \\
\text { Break } \\
\text { (MPa) }\end{array}$ & $\begin{array}{c}\text { Elongation } \\
\text { at Peak } \\
(\%)\end{array}$ & $\begin{array}{c}\text { Elongation } \\
\text { at Break } \\
(\%)\end{array}$ & $\begin{array}{l}\text { Young's } \\
\text { Modulus } \\
\text { (MPa) }\end{array}$ & $\begin{array}{c}\text { Poisson's } \\
\text { Ratio }\end{array}$ \\
\hline$(A+C) 4$ & 141.40 & 3.04 & 127.26 & 3.8 & 45.0 & 40.5 & 5.0 & 6.5 & 740.131 & 1.539 \\
\hline$(A+C) 9$ & 117.63 & 2.85 & 105.87 & 3.4 & 37.5 & 33.7 & 4.3 & 5.7 & 657.894 & 1.145 \\
\hline$(A+C) 10$ & 88.90 & 2.95 & 80.01 & 3.1 & 28.3 & 25.5 & 5.0 & 5.5 & 479.661 & 0.790 \\
\hline
\end{tabular}

Overall, it was confirmed that the highest ultimate tensile strength was achieved in double-sized copper particles with a composition of 3\% (200 and 400 mesh) copper particles and $97 \%$ ABS, whereas the lowest ultimate tensile strength was achieved using the composition of $6 \%$ (100 and 400 mesh) copper particles and $94 \%$ ABS. 


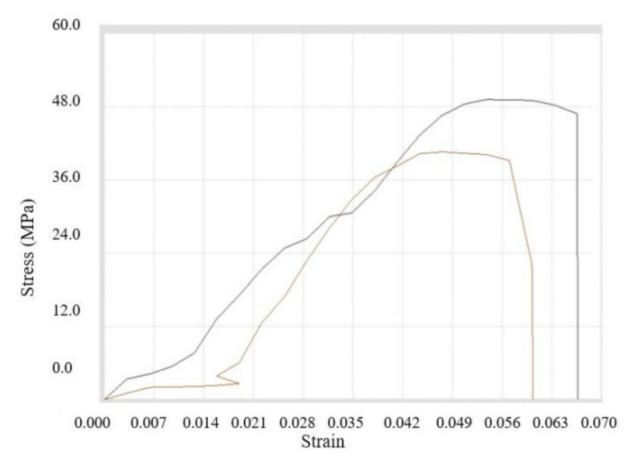

(a)

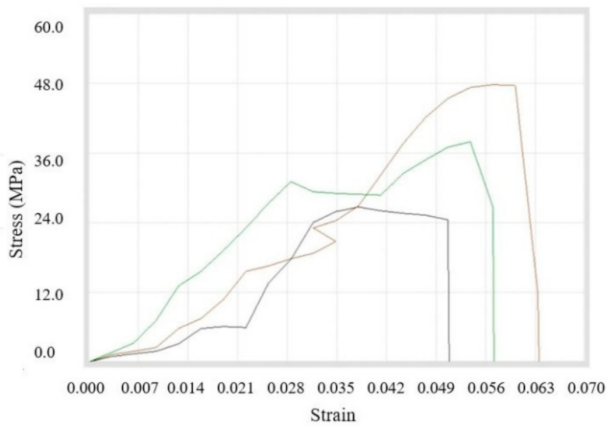

(b)

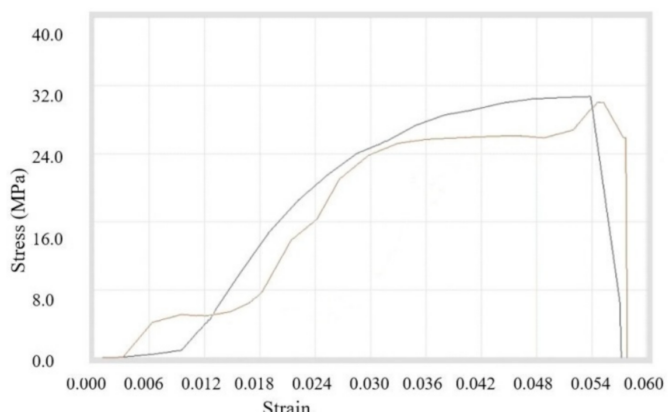

(c)

Figure 13. Stress-strain Curves for $(\mathbf{a})(A+C) 4,(\mathbf{b})(A+C) 9$, and $(\mathbf{c})(B+C) 10$ filament samples.

\subsubsection{Tensile Testing of Triple Copper Particle with ABS}

The mixture of all three sizes of copper particles at different proportions was prepared with $\mathrm{ABS}$ as the matrix. It was concluded that peak properties were minimum during $1 \%$ addition whereas maximum for $3 \%$ addition of copper particles. The data are shown in Table 13 with stress-strain curves in Figure 14a-c.

Table 13. Tensile testing of triple-sized particle reinforcements at different proportions.

\begin{tabular}{|c|c|c|c|c|c|c|c|c|c|c|}
\hline $\begin{array}{c}\text { Material } \\
\text { Composition }\end{array}$ & $\begin{array}{l}\text { Peak } \\
\text { Load } \\
(\mathrm{N})\end{array}$ & $\begin{array}{c}\text { Peak } \\
\text { Elongation } \\
(\mathrm{mm})\end{array}$ & $\begin{array}{l}\text { Break } \\
\text { Load } \\
\text { (N) }\end{array}$ & $\begin{array}{c}\text { Break } \\
\text { Elongation } \\
(\mathrm{mm})\end{array}$ & $\begin{array}{l}\text { Strength } \\
\text { at Peak } \\
\text { (MPa) }\end{array}$ & $\begin{array}{c}\text { Strength } \\
\text { at Break } \\
\text { (MPa) }\end{array}$ & $\begin{array}{c}\text { Elongation } \\
\text { at Peak } \\
(\%)\end{array}$ & $\begin{array}{c}\text { Elongation } \\
\text { at Break } \\
(\%)\end{array}$ & $\begin{array}{l}\text { Young's } \\
\text { Modulus } \\
\text { (MPa) }\end{array}$ & $\begin{array}{c}\text { Poisson's } \\
\text { Ratio }\end{array}$ \\
\hline$(A+B+C) 4$ & 148.83 & 2.66 & 133.95 & 3.4 & 47.4 & 42.7 & 4.3 & 5.7 & 890.977 & 1.451 \\
\hline$(A+B+C) 9$ & 127.27 & 3.10 & 114.54 & 3.6 & 40.5 & 36.5 & 5 & 6 & 653.225 & 1.314 \\
\hline$(A+B+C) 10$ & 136.10 & 2.41 & 122.49 & 3.0 & 43.3 & 39.0 & 4 & 4.7 & 898.340 & 1.17 \\
\hline
\end{tabular}

The above analysis indicates that there was a decrease in ultimate tensile strength while adding triple-sized copper particles from 1\% to 3\%. Further addition of copper particles (upto 6\%) increased the ultimate tensile strength.

A variation in stress-strain curves of different replications with same composition was noticed. This can be attributed to a variation in diameter of filament during extrusion. The filament with $1.75 \mathrm{~mm}$ diameter was extruded with the tolerance of $\pm 0.5 \mathrm{~mm}$. Hence, the overall filament diameter of filament was achieved within the range $1.70-1.80 \mathrm{~mm}$. Moreover, this diameter was not uniform along the length, which resulted in variation in mass and volume. Islam et al. [37] experienced similar dimensional variation in filaments, which resulted in significant variation in tensile behavior of T700 carbon fiber. The variation in stress-strain curves during the same experiments with different replications was demonstrated by Rane et al. [38]. During the tensile testing, crazing phenomenon occurred at multiple regions, which resulted in significant disagreement between stress-strain curves. The defects in 3d-printed tensile test specimens and changes in manufacturing conditions 
tend to exhibit significant differences in mechanical strength $[39,40]$. In the present experiment, the impact of different copper particle sizes and their combinations were tested to determine tensile strength. At the initial stages of new material development, such problems of dimensional variations were evident and also reported by previous studies during the extrusion of polymers and polymer composites [41,42]. The variation in diameter of filament can be reduced by studying and controlling the critical parameters during extrusion. During commercialization of new material, the noise factors can be removed, which would improve the consistency in tensile test measurements.

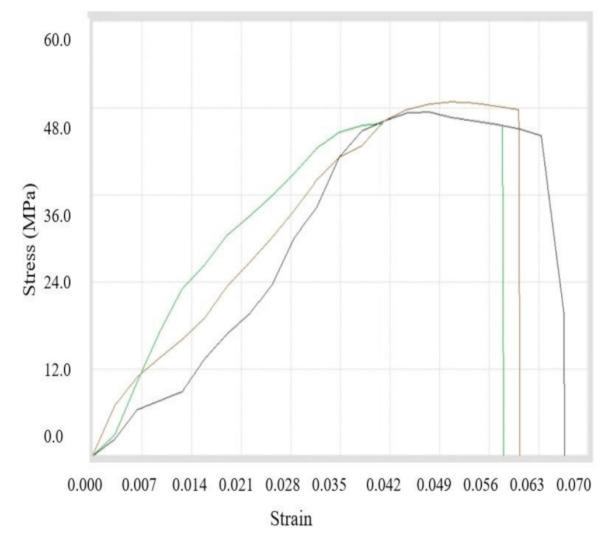

(a)

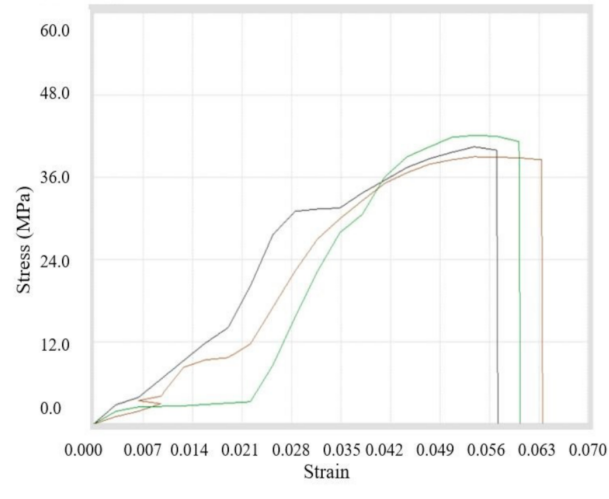

(b)

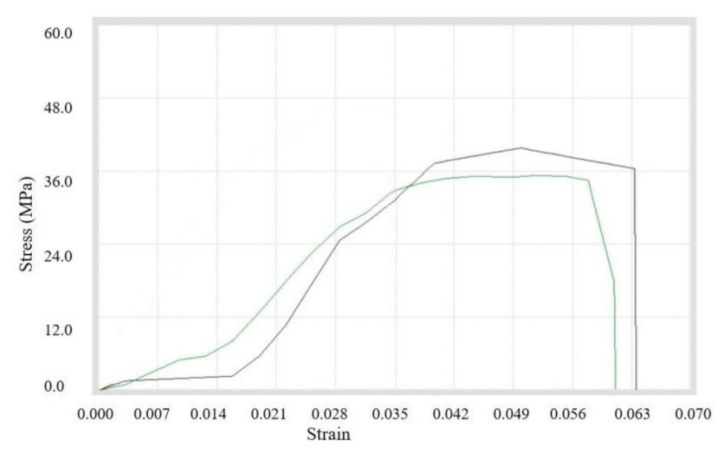

(c)

Figure 14. Stress-strain curves for (a) $(A+B+C) 4$, (b) $(A+B+C) 9$, and (c) $(A+B+C) 10$ filament samples.

\subsection{Material Characterization}

\subsubsection{FTIR Analysis}

FTIR method was used to characterize the functional groups obtained at different frequencies while adding different-sized copper particles in ABS and nylon 6. The IR spectra of base material depends upon the shape and size of the reinforced particles [43]. FTIR of 200 mesh-sized copper particles with $2.5 \%$ addition in nylon 6 is shown in Figure 15a. With an addition of $2.5 \%$ copper in nylon 6 material, we get an initial sharp peak at a frequency of $2920.99 \mathrm{~cm}^{-1}$, which indicates $\mathrm{CH}_{2}$ asymmetric stretching. Another absorption was noted at $1724.87 \mathrm{~cm}^{-1}$, which represents the stretching vibration of $\mathrm{C}=\mathrm{O}$ bond. Similar absorption was experienced by Charles et al. [44] after the addition of glass fiber in nylon 6 . The smaller peaks at frequencies of $1633.13 \mathrm{~cm}^{-1}$ and $1536.40 \mathrm{~cm}^{-1}$ highlight the presence of Amide I and Amide II. However, the lower reflectance was noticed as compared to pure Nylon 6, which occurred due to a larger size of copper particles. The aggregations caused by large-sized particles resulted in higher absorbance. Also, the peak observed at $696.84 \mathrm{~cm}^{-1}$ indicates the higher contribution of copper particles during shift in wavelength and absorption rate. This peak in spectrum was also reported by Betancourt-Galindo et al. [45] 
during the synthesis of copper nanoparticles. This aggregation of large-sized particles also reduced the MFI of composite prepared with 200 mesh copper particles (B2) as compared to 100 mesh (A2) and 200 mesh (C2) (see Table 3). The FTIR of samples with 5\% 400 mesh copper particles in Nylon6 is shown in Figure 15b. The frequencies obtained are $2927.03 \mathrm{~cm}^{-1}$ and $3292.37 \mathrm{~cm}^{-1}$, which indicates the sp and sp $\mathrm{sp}^{2}$ have the chemical bond $\mathrm{C}-\mathrm{H}$. Because most organic compounds feature $\mathrm{C}-\mathrm{H}$ bonds, a relevant guideline is that absorption between 2850 and $3000 \mathrm{~cm}^{-1}$ is caused by sp3 C-H stretching, whereas absorption beyond $3000 \mathrm{~cm}^{-1}$ is caused by sp2 C-H stretching or sp C-H stretching if the wavelength is near $3300 \mathrm{~cm}^{-1}$. As the s nature of the $\mathrm{C}-\mathrm{H}$ bond increased, so did its strength. It also has two peaks with sharp ends achieved at frequencies of $1636.27 \mathrm{~cm}^{-1}$ and $1535.05 \mathrm{~cm}^{-1}$ making a $\mathrm{C}=\mathrm{N}$. The $\mathrm{C}=\mathrm{N}$ double bond is around twice as strong as a $\mathrm{C}-\mathrm{N}$ single bond, while a C-N triple bond has roughly the same strength as a double bond. The 400 mesh-sized copper particles show comparatively greater adhesion and bonding with polymer chains. This phenomenon validates the higher MFI and tensile strength of composites with 400 mesh-sized copper particles as compared to 100 and 200 mesh sizes.

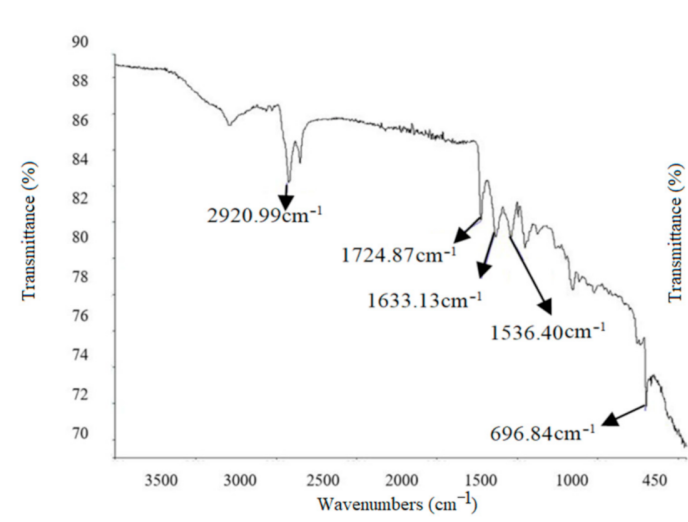

(a)

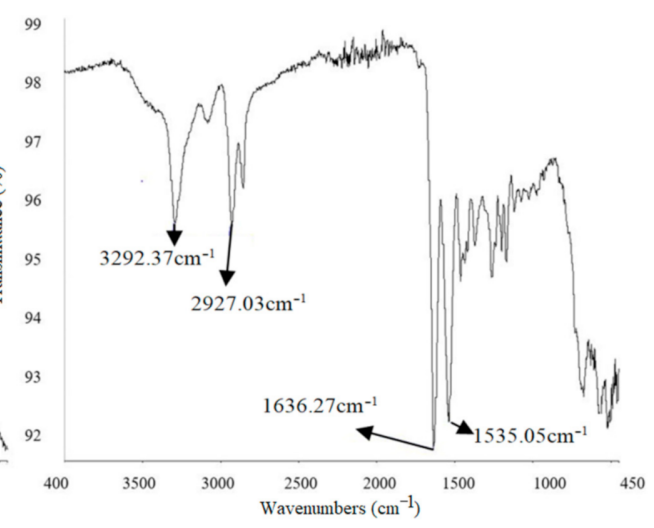

(b)

Figure 15. FTIR graphs of Nylon composites: (a) B2 and (b) C3.

FTIR for ABS with different ratios of copper particles are shown in Figures 16 and 17. In the case of $C 5$ and $C 6$ composition, the sharp peak at $2921.27 \mathrm{~cm}^{-1}$ represents the $\mathrm{sp}^{2}$ spectrum having a chemical bond of C-H. C-H stretches only below $3000 \mathrm{~cm}^{-1}$ in compounds that do not have a $\mathrm{C}=\mathrm{C}$ bond. As the s nature of the $\mathrm{C}-\mathrm{H}$ bond increased, so did its strength. The depth of the potential energy well associated with a $\mathrm{C}-\mathrm{H}$ is measured by bond strength. The stiffness of a bond is a measurement of the amount of energy required to compress or stretch it. The firmer bond is frequently associated with a deeper potential energy surface, despite the fact that these are separate qualities. The peak at a frequency near $1500 \mathrm{~cm}^{-1}$ represents $\mathrm{C}=\mathrm{N}$ chemical structure.

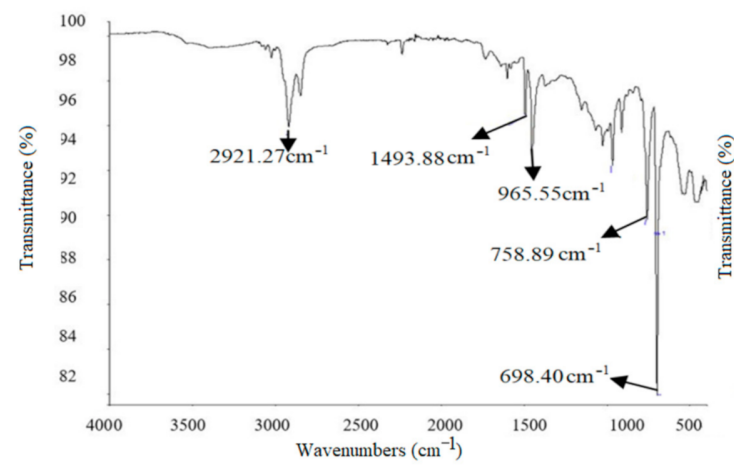

(a)

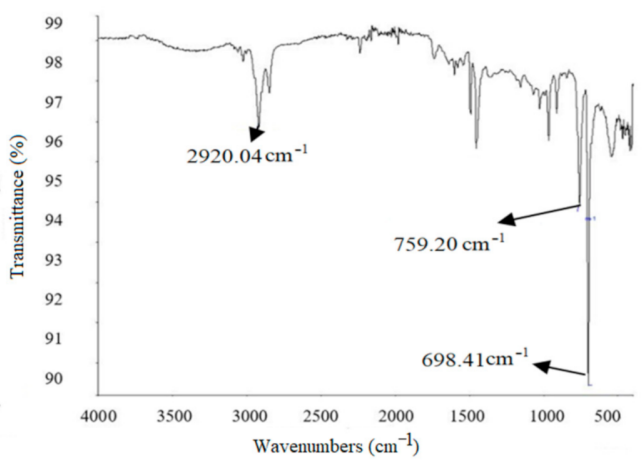

(b)

Figure 16. FTIR graphs of ABS composites: (a) C5 and (b) C6. 


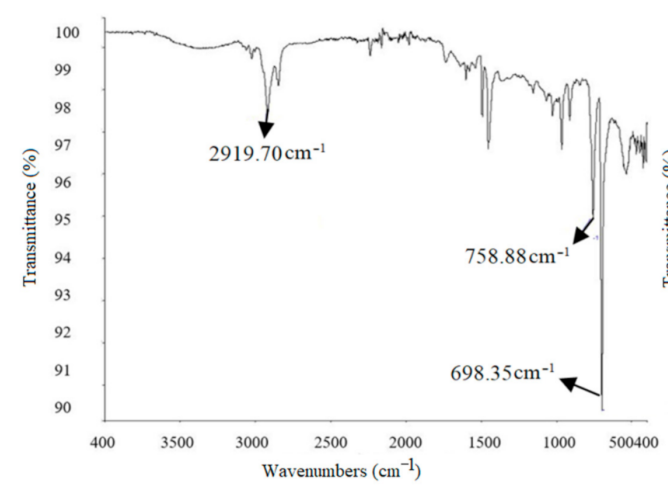

(a)

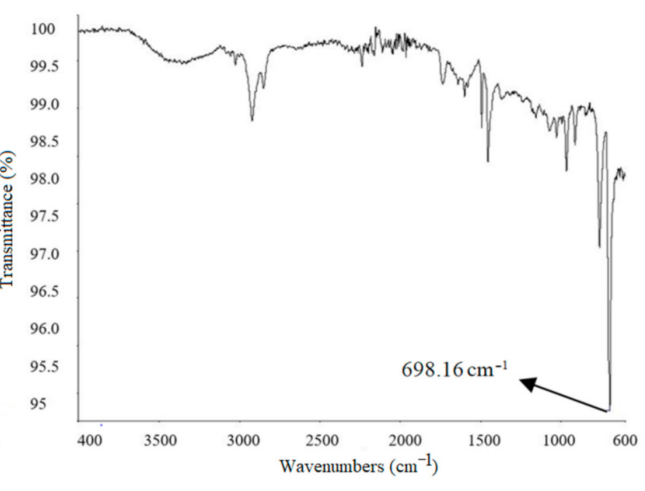

(b)

Figure 17. FTIR graphs of ABS composites (a) C7 and (b) C8.

For C mixture, three peaks were examined from which one peak was $2920.04 \mathrm{~cm}^{-1}$, which means $\mathrm{sp}^{2}$ spectrum making $\mathrm{C}-\mathrm{H}$ chemical bonding. The other two peaks were nearer to $700 \mathrm{~cm}^{-1}$, making $\mathrm{C}-\mathrm{Cl}$ bonding.

Lastly, when $C 7$ and $C 8$ were tested, then the highest peak was only obtained at the frequency $698.15 \mathrm{~cm}^{-1}$, from which it was concluded that while increasing the frequency, the value of $v(\mathrm{nu})$ was decreasing. FTIR images for these mixtures are shown in Figure 15.

The FTIR analysis of composite samples reveals the presence of $\mathrm{C}-\mathrm{H}$ chemical bonding, which is also supported by the higher values of tensile strength and MFI as compared to pure materials. This phenomenon also supports the significant increase in MFI and tensile strength of composites prepared with 400 mesh copper particles. The smaller size of particles ensures uniform dispersion and chemical bonding between the amorphous molecular chains as compared to larger particles [46,47]. The optimum composition and size of copper particles improved the rheology and mechanical stability of samples, and the phenomenon was supported by FTIR results.

\subsubsection{SEM Analysis}

SEM analysis was done to study the fracture behavior and failure of composite filament during tensile loading. Figure 18 a shows the SEM image of $2.5 \% \mathrm{C}$ copper with $97.5 \%$ nylon 6 , which reflects that the material has a higher elasticity with no voids. These images support the higher fluidity and mechanical strength of composites prepared with 400 mesh copper particles. Sierra-Avila et al. [48] also performed similar experimentation on composites of nylon 6 and copper nanoparticles. It was investigated through SEM analysis that the composition having $0.10 \%$ copper particles in nylon 6 had a high rate of dispersion rate whilst showing spherical and long-shape nanowires in it. Also, the composition of nylon 6 and copper nanoparticles resulted in the highest tensile strength and lowest elongation at break. Unal et al. [49] also experienced a similar phenomenon during SEM analysis, in which the addition of fillers such as wollastonite, kaolin, powder, and glass particles reduced the voids and increased the flexibility of polymer composite. In Figure $18 \mathrm{~b}$, the SEM image was done for the composition of $1 \%$ B copper and $99 \%$ ABS material, which represents a lot of voids and stiffer material. The lower values of strength and MFI of ABS samples can be explained by these images. Figure 18c represents the mixture with $6 \%$ copper and $94 \%$ ABS. The voids were reduced with an increase in copper percentage. As a result, the material became comparatively more elastic as compared to $1 \%$ loading. Figure $18 \mathrm{~d}$ shows the mixture of $10 \%$ copper and $90 \%$ ABS where the voids are absent, leading to high elasticity and tensile strength. So, it was evident from the SEM images that while increasing the 400 mesh copper percentage in ABS material, the elasticity increased with a reduction in voids. 


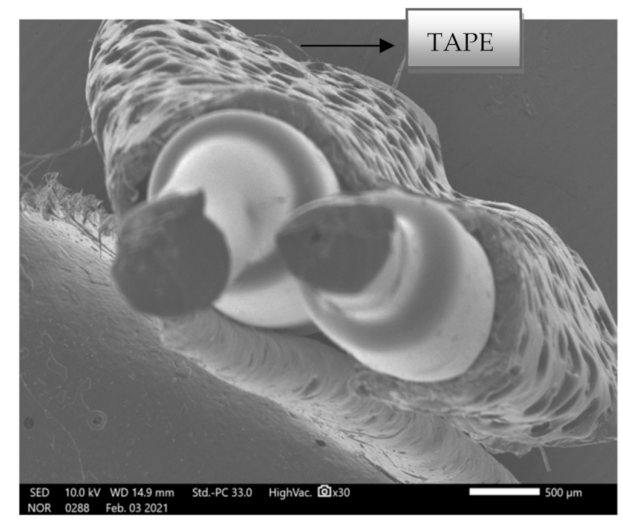

(a)

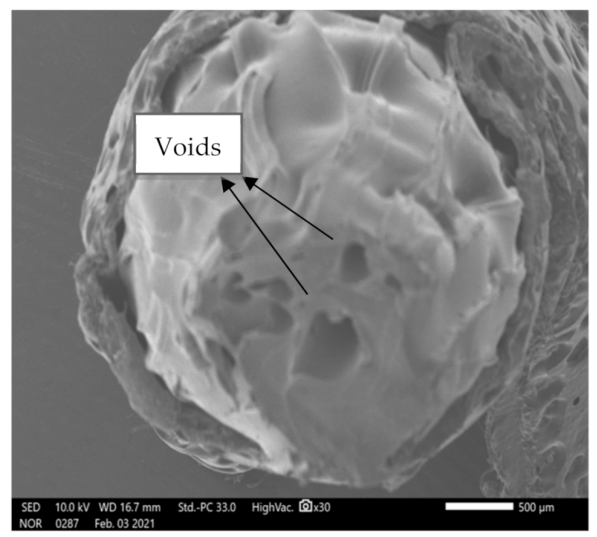

(c)

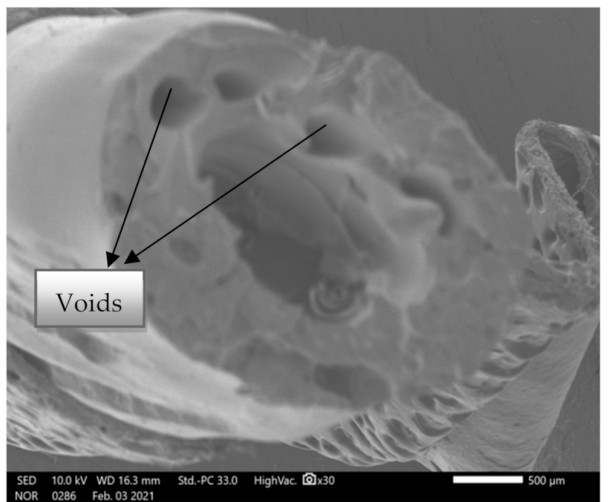

(b)

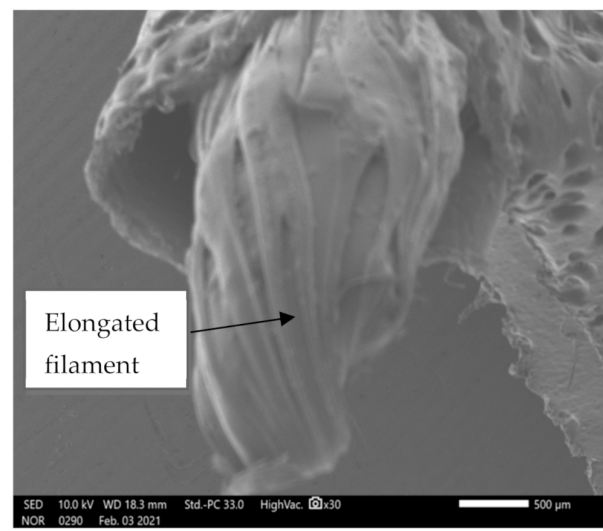

(d)

Figure 18. SEM Images of (a) C2, (b) B4, (c) B10, and (d) C8.

\subsection{Electrical and Thermal Conductivity}

After melt flow and mechanical strength analysis, the electrical and thermal conductivity of copper-reinforced polymer composites was investigated to highlight their functionality for vast engineering applications. The electrical conductivity testing was done for the compositions of $B 5, B 6, B 7$, and $B 8$ having $2.5 \%, 5 \%, 8 \%$, and $10 \%$ copper particle reinforcement respectively. The filaments samples with diameter $0.203 \mathrm{~m}$ and length $0.05 \mathrm{~mm}$ were prepared for electrical conductivity testing. The readings obtained from the testing confirm that the resistivity is decreasing as the percentage of copper is increased in ABS polymer. Conversely, the electrical conductivity of polymer composite is increased with copper concentration. The measurements were obtained after the testing, and hence the graphical representation of electrical conductivity is shown Figure 19. The increase in copper particle concentration assists the flow of electricity. This property of composite polymer can be used for the development of functional prototypes, $4 \mathrm{~d}$ materials, and smart materials.

During the thermal conductivity measurement, disc-shaped samples with a mass of $0.25 \mathrm{~kg}$ and area $0.007853 \mathrm{~m}^{2}$ were prepared through FDM. A variation in thermal conductivity of composites was noticed for every composition. Figure 20 plots a relationship between copper particle concentration and thermal conductivity of samples. An increase in particle concentration in ABS improves the ability to conduct heat as more particles are dispersed, which act as heat carriers. 


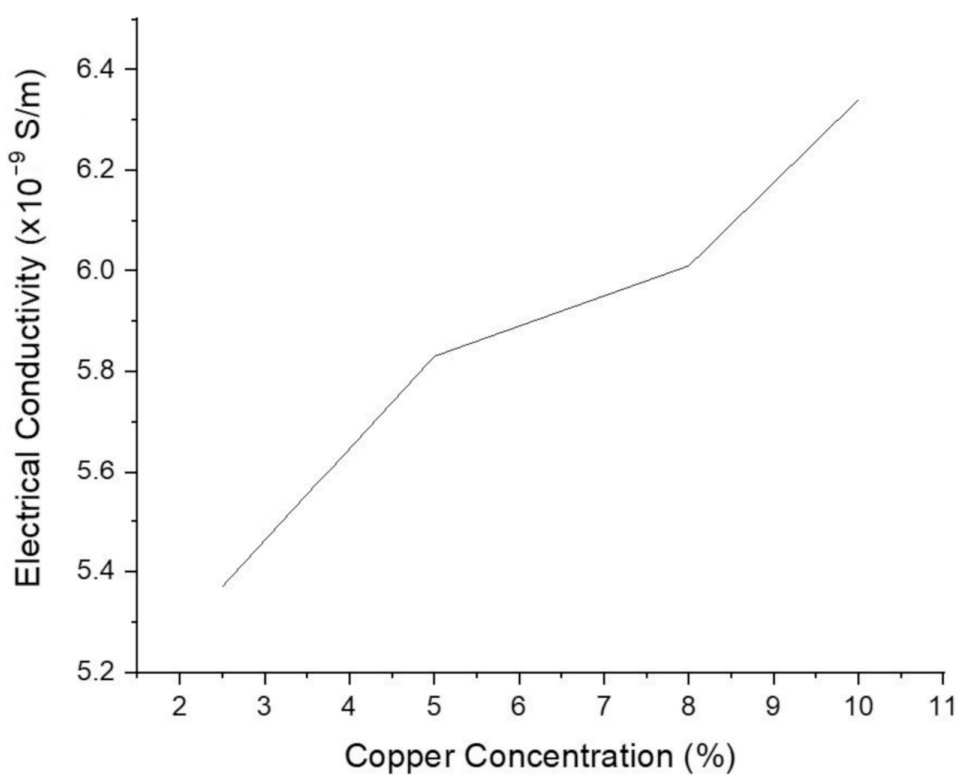

Figure 19. Electrical conductivity of copper-reinforced polymer composites.

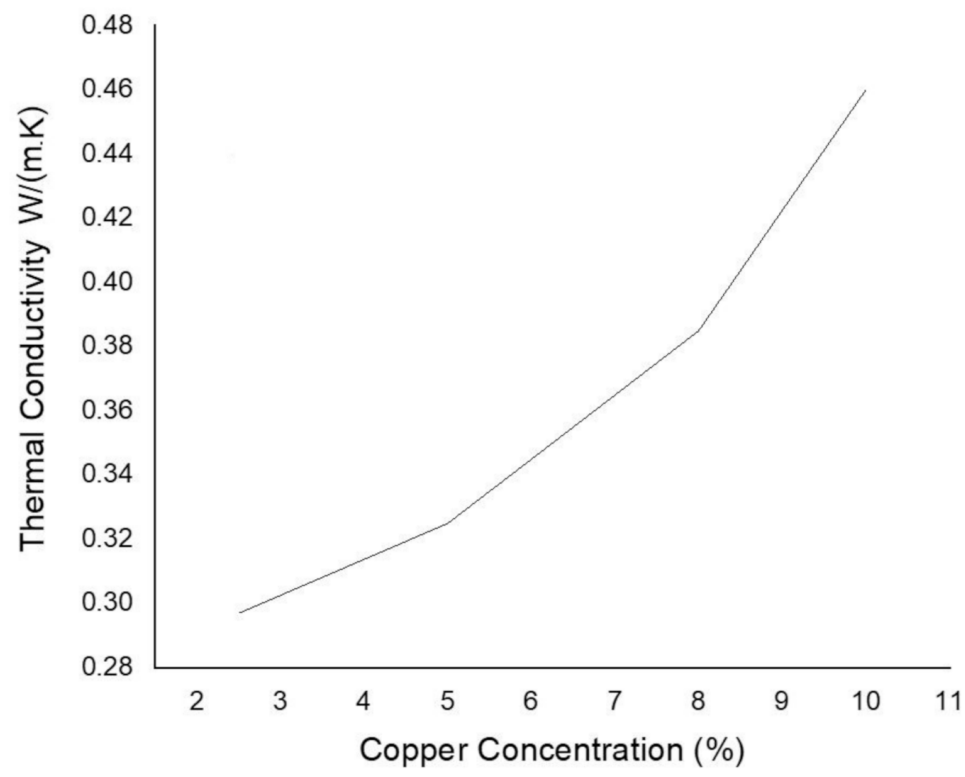

Figure 20. Thermal conductivity of copper-reinforced polymer composites.

\section{Conclusions}

The melt flow rate, mechanical, morphological, electrical, and thermal properties of copper-reinforced ABS and nylon 6 filaments were investigated to highlight their applicability for $3 \mathrm{~d}$ printing applications. An attempt was made to investigate the scope of using 3D-printed copper-reinforced polymers for fabrication of different industrial application parts from which the higher mechanical, thermal, and electrical conductivity can be obtained. The copper particles with three different sizes were used as reinforcement and the impact of different combinations and compositions was investigated. It was noticed that MFI firstly increased with the addition of copper particles up to a particular point, after which constant fluidity could be obtained, which could be used to prepare feedstock filament. The melt flow rate and tensile strength improved by using small-sized copper particles. Overall, it was noticed that the fluidity and tensile strength obtained within the range of $5-8 \%$ addition of copper particles (200 and 400 mesh) is suitable for making the filament for FDM using a screw extruder. It was evident from FTIR images that this 
composition made the interfacial chemical bond, which improves bonding strength. Also, the samples prepared with 10\% copper reinforcements exhibited the highest thermal and electrical conductivity. The findings of this can help to prepare feedstock filament for FDM process to manufacture customized electronic components with desired mechanical strength. An efficient heat transfer can be ensured by using copper particles in polymers, which would also enhance the mechanical stability of components.

Author Contributions: Conceptualization, B.S., R.K., J.S.C., S.S., C.I.P. and M.L.S.; methodology, B.S., R.K., J.S.C., S.S. and C.I.P.; software, B.S., R.K., J.S.C., S.S. and C.I.P.; validation, C.I.P. and M.L.S.; formal analysis, C.I.P., M.L.S.; investigation, B.S., R.K., J.S.C., S.S., C.I.P. and M.L.S.; resources, B.S., R.K., J.S.C., S.S., C.I.P.; data curation, B.S., R.K., J.S.C., S.S.; writing-original draft preparation, B.S., R.K., J.S.C., S.S., C.I.P.; writing-review and editing, B.S., R.K., J.S.C., S.S., C.I.P. and M.L.S.; visualization, M.L.S., R.M.; supervision, M.L.S., R.M.; project administration, M.L.S., R.M.; funding acquisition. All authors have read and agreed to the published version of the manuscript.

Funding: This research received no external funding.

Institutional Review Board Statement: Not applicable.

Informed Consent Statement: Not applicable.

Data Availability Statement: The data presented in this study are available upon request from the corresponding author.

Conflicts of Interest: The authors declare no conflict of interest.

\section{References}

1. Mohammed, L.; Ansari, M.N.M.; Pua, G.; Jawaid, M.; Islam, S. A review on natural fiber reinforced polymer composite and its applications. Int. J. Polym. Sci. 2015, 2015, 1-15. [CrossRef]

2. Gdoutos, E.E. Composite Materials. Intern. Var. Thermoelast. 2020, 263, 333-352. [CrossRef]

3. Aleksendrić, D.; Carlone, P. Introduction to composite materials. Soft Comput. Des. Manuf. Compos. Mater. 2015, 2015, 1-5. [CrossRef]

4. Vasiliev, V.V.; Morozov, E.V. Introduction. Adv. Mech. Compos. Mater. Struct. 2018. [CrossRef]

5. Komus, A.; Beley, N. Composite Applications for Ground Transportation; Elsevier BV: Amsterdam, The Netherlands, 2018; Volume 3, pp. $420-438$.

6. Miracle, D.B.; Donaldson, S.L.; Nutt, S.R.; Wallenberger, F.T.; Watson, J.C.; Li, H.; Wool, R.P.; Khot, S.N.; Wilson, D.; Dicarlo, J.; et al. Introduction to Composites. Composites 2001, 21, 3-17. [CrossRef]

7. Boparai, K.; Singh, R.; Singh, H. Comparison of tribological behaviour for Nylon6- $\mathrm{Al}_{-} \mathrm{Al}_{2} \mathrm{O}_{3}$ and $\mathrm{ABS}$ parts fabricated by fused deposition modelling. Virtual Phys. Prototyp. 2015, 10, 59-66. [CrossRef]

8. Tekce, H.S.; Kumlutas, D.; Tavman, I.H. Effect of particle shape on thermal conductivity of copper reinforced polymer compo-sites. J. Reinf. Plast. Compos. 2007, 26, 113-121. [CrossRef]

9. León-Patiño, C.A.; Rodriguez-Ortiz, G.; Aguilar-Reyes, E.A. Fabrication and thermal properties of copper-based composites. In Proceedings of the Materials Science and Technology Conference and Exhibition, Pittsburgh, PA, USA, 25-29 October 2009; pp. 1848-1855.

10. Singh, B.; Kumar, R.; Chohan, J.S. Polymer matrix composites in 3D printing: A state of art review. Mater. Today Proc. 2020, 33, 1562-1567. [CrossRef]

11. Boparai, K.S.; Singh, R.; Singh, H. Development of rapid tooling using fused deposition modeling: A review. Rapid Prototyp. J. 2016, 22, 281-299. [CrossRef]

12. Bolcu, D.; Stănescu, M.M. A study of the mechanical properties of composite materials with a dammar-based hybrid matrix and two types of flax fabric reinforcement. Polymers 2020, 12, 1649. [CrossRef]

13. Hamzah, K.A.; Yeoh, C.K.; Noor, M.M.; Teh, P.L.; Aw, Y.Y.; Sazali, S.A.; Wan Ibrahim, W.M.A. Mechanical properties and thermal and electrical conductivity of 3D printed ABS-copper ferrite composites via 3D printing technique. J. Thermoplast. Compos. Mater. 2019. [CrossRef]

14. Shahmirzadi, S.R.; Yousefi, A.A.; Naderpour, N. Morphology and Rheological Properties of Copper-Polypropylene Composite as a Candidate for Fusion Deposition Modeling (FDM) Filament. In Proceedings of the 12th International Seminar on Polymer Science and Technology, Tehran, Iran, 9-12 November 2016.

15. Isa, N.M.A.; Saude, N.; Ibrahim, M.; Hamid, S.M.; Kamarudin, K. A Study on Melt Flow Index on Copper-ABS for Fused Deposition Modeling (FDM) Feedstock. In Applied Mechanics and Materials; Trans Tech Publications Ltd.: Stafa-Zurich, Switzerland, 2015; Volume 773, pp. 8-12.

16. Nikzad, M.; Masood, S.H.; Sbarski, I. Thermo-mechanical properties of a highly filled polymeric composites for Fused Deposition Modeling. Mater. Des. 2011, 32, 3448-3456. [CrossRef] 
17. Singh, P.; Ghosh, A.K. Torsional, tensile and structural properties of acrylonitrile-butadiene-styrene clay nanocomposites. Mater. Des. 2014, 55, 137-145. [CrossRef]

18. Zou, C.; Chen, Z.; Guo, E.; Kang, H.; Fan, G.; Wang, W.; Li, R.; Zhang, S.; Wang, T. A nano-micro dual-scale particulate-reinforced copper matrix composite with high strength, high electrical conductivity and superior wear resistance. RSC Adv. 2018, 8, 30777-30782. [CrossRef]

19. Boudenne, A.; Ibos, L.; Fois, M.; Majesté, J.C.; Géhin, E. Electrical and thermal behavior of polypropylene filled with copper parti-cles. Compos. Part A Appl. Sci. Manuf. 2005, 36, 1545-1554. [CrossRef]

20. Moore, J. Acrylonitrile-butadiene-styrene (ABS)—A review. Composites 1973, 4, 118-130. [CrossRef]

21. Chohan, J.S.; Singh, R.; Boparai, K.S. Thermal and surface characterization of ABS replicas made by FDM for rapid tool-ing applications. Rapid Prototyp. J. 2018, 24, 28-36. [CrossRef]

22. Hale, W.; Pessan, L.; Keskkula, H.; Paul, D. Effect of compatibilization and ABS type on properties of PBT/ABS blends. Polymers 1999, 40, 4237-4250. [CrossRef]

23. Li, M.; Zinkle, S. Physical and mechanical properties of copper and copper alloys. Compr. Nucl. Mater. 2012, 4, 667-690. [CrossRef]

24. Singh, R.; Bedi, P.; Fraternali, F.; Ahuja, I.P. Effect of single particle size, double particle size and triple particle size $\mathrm{Al}_{2} \mathrm{O}_{3}$ in Ny-lon-6 matrix on mechanical properties of feed stock filament for FDM. Compos. Part B Eng. 2016, 106, 20-27. [CrossRef]

25. Popov, K.; Krstic, S.; Pavlovic, M. The critical apparent density for the free flow of copper powder. J. Serb. Chem. Soc. 2003, 68, 511-513. [CrossRef]

26. BIS 460-1. Specification for Test Sieves; Bureau of Indian Standards: New Delhi, India, 1985.

27. Razvarz, S.; Jafari, R.; Vargas-Jarillo, C. Modelling and analysis of flow rate and pressure head in pipelines. In Proceedings of the 2019 16th International Conference on Electrical Engineering, Computing Science and Automatic Control (CCE), Mexico City, Mexico, 11-13 September 2019; pp. 1-6.

28. Lange, B.; Recknagel, S.; Czerwensky, M.; Matschat, R.; Michaelis, M.; Peplinski, B.; Panne, U. Analysis of pure copper-A comparison of analytical methods. Microchim. Acta 2008, 160, 97-107. [CrossRef]

29. Mertz, A.M.; Mix, A.W.; Baek, H.M.; Giacomin, A.J. Understanding melt index and ASTM D1238. J. Test. Eval. 2013, 41, 50-62. [CrossRef]

30. Shenoy, A.V.; Saini, D.R. Melt flow index: More than just a quality control rheological parameter. Part I. Adv. Polym. Technol. 1986, 6, 1-58. [CrossRef]

31. Huerta, E.; Corona, J.E.; Oliva, A.I.; Avilés, F.; González-Hernández, J. Universal testing machine for mechanical properties of thin materials. Rev. Mex. Fis. 2010, 56, 317-322.

32. Berthomieu, C.; Hienerwadel, R. Fourier transform infrared (FTIR) spectroscopy. Photosynth. Res. 2009, 101, 157-170. [CrossRef]

33. Goldstein, J.I.; Newbury, D.E.; Michael, J.R.; Ritchie, N.W.; Scott, J.H.J.; Joy, D.C. Scanning Electron Microscopy and X-ray Microanalysis; Springer: Berlin/Heidelberg, Germany, 2017.

34. Sombatsompop, N.; Wood, A.K. Measurement of thermal conductivity of polymers using an improved Lee's Disc apparatus. Polym. Test. 1997, 16, 203-223. [CrossRef]

35. Leidheiser, H.; Deck, P.D.; Morad, M.; Davies, N.; Kaplan, J.; Lux, H. Chemistry of the metal-polymer interfacial region. Science 1988, 241, 1176-1181. [CrossRef]

36. Vu, M.C.; Jeong, T.; Kim, J.; Choi, W.K.; Kim, D.H.; Kim, S. 3D printing of copper particles and poly(methyl methacrylate) beads containing poly(lactic acid) composites for enhancing thermomechanical properties. J. Appl. Polym. Sci. 2021, $138,49776$. [CrossRef]

37. Islam, F.; Joannès, S.; Bucknell, S.; Leray, Y.; Bunsell, A.; Laiarinandrasana, L. Investigation of tensile strength and dimensional variation of T700 carbon fibres using an improved experimental setup. J. Reinf. Plast. Compos. 2019, 39, 144-162. [CrossRef]

38. Rane, R.; Kulkarni, A.; Prajapati, H.; Taylor, R.; Jain, A.; Chen, V. Post-Process effects of isothermal annealing and initially applied static uniaxial loading on the ultimate tensile strength of fused filament fabrication parts. Materials 2020, 13, 352. [CrossRef]

39. Fayazbakhsh, K.; Movahedi, M.; Kalman, J. The impact of defects on tensile properties of 3D printed parts manu-factured by fused filament fabrication. Mater. Today Commun. 2019, 18, 140-148. [CrossRef]

40. Zhang, H.; Yao, Y.; Zhu, D.; Mobasher, B.; Huang, L. Tensile mechanical properties of basalt fiber reinforced poly-mer composite under varying strain rates and temperatures. Polym. Test. 2016, 51, 29-39. [CrossRef]

41. Masood, S.; Song, W. Development of new metal/polymer materials for rapid tooling using Fused deposition modelling. Mater. Des. 2004, 25, 587-594. [CrossRef]

42. Zhao, X.; Chen, F.; Li, Y.; Lu, H.; Zhang, N.; Ma, M. Bioinspired ultra-stretchable and anti-freezing conductive hydrogel fibers with ordered and reversible polymer chain alignment. Nat. Commun. 2018, 9, 1-8. [CrossRef]

43. Rendon, J.L.; Serna, C.J. IR spectra of powder hematite: Effects of particle size and shape. Clay Miner. 1981, 16, 375-382. [CrossRef]

44. Charles, J.; Ramkumaar, G.R.; Azhagiri, S.; Gunasekaran, S. FTIR and Thermal Studies on Nylon-66 and $30 \%$ Glass Fibre Reinforced Nylon-66. E-J. Chem. 2009, 6, 23-33. [CrossRef]

45. Betancourt-Galindo, R.; Reyes-Rodriguez, P.Y.; Puente-Urbina, B.A.; Avila-Orta, C.A.; Rodríguez-Fernández, O.S.; Cadenas-Pliego, G.; Lira-Saldivar, R.H.; García-Cerda, L.A. Synthesis of Copper Nanoparticles by Thermal Decomposition and Their Antimicrobial Properties. J. Nanomater. 2014, 2014, 1-5. [CrossRef] 
46. Wang, H.; Zhang, Z.H.; Hu, Z.Y.; Song, Q.; Yin, S.P.; Kang, Z.; Li, S.L. Improvement of interfacial interaction and mechanical proper-ties in copper matrix composites reinforced with copper coated carbon nanotubes. Mater. Sci. Eng. A 2018, 715, 163-173. [CrossRef]

47. Wei, Q.; Xu, Q.; Cai, Y.; Wang, Y. Evaluation of the interfacial bonding between fibrous substrate and sputter coated copper. Surf. Coat. Technol. 2008, 202, 4673-4680. [CrossRef]

48. Sierra-Ávila, R.; Pérez-Alvarez, M.; Valdez-Garza, J.; Avila-Orta, C.A.; Jiménez-Regalado, E.J.; Mata-Padilla, J.M.; Soto-Castruita, E.; Cadenas-Pliego, G. Synthesis and thermomechanical characterization of Nylon 6/Cu nanocomposites produced by an ultrasound-assisted extrusion method. Adv. Mater. Sci. Eng. 2018, 2018, 1-10. [CrossRef]

49. Unal, H.; Mimaroglu, A.; Alkan, M. Mechanical properties and morphology of nylon-6 hybrid composites. Polym. Int. 2003, 53, 56-60. [CrossRef] 